\title{
Measurements of Mantle Wave Velocities and Inversion for Lateral Heterogeneity and Anisotropy 1. Analysis of Great Circle Phase Velocities
}

\author{
ICHIRO NAKANISHI ${ }^{1}$ AND DON L. ANDERSON \\ Seismological Laboratory California Institute of Technology
}

\begin{abstract}
Long-period (100-330 s) fundamental-mode Love and Rayleigh waves have been processed to measure the great circle phase velocities for about 200 and 250 paths, respectively. The observations are inverted for regionalized phase velocities and for an even-order harmonic expansion of the lateral velocity heterogeneity. The regionalized inversions achieve a maximum variance reduction of about $65 \%$ and $85 \%$ for the Love and the Rayleigh wave data, respectively. The $l_{\max }=2$ inversions give a maximum variance reduction of about $60 \%$ and $90 \%$ for Love and Rayleigh waves, respectively. The $l_{\max }=8$ inversion does not make a large improvement in the fit. The Love wave phase velocities have more power in $l=4$ and 6 , relative to $l=2$, than the Rayleigh waves. For both Love and Rayleigh wave data the sectoral component dominates the $l=2$ harmonics, and this component is stable if we increase $l_{\max }$ from 2 to 6 . Heat flow also has strong sectoral components $(l m=22)$, which are approximately in phase with those of the phase velocities. The $l=2$ harmonics of the nonhydrostatic geoid are dominated by large zonal $(l m=20)$ and moderate sectoral components. The sectoral components are in phase with those of the phase velocities. The sectoral pattern of heat flow and phase velocity is controlled by high heat flow-low velocity of the East Pacific Rise and western North America, which is reinforced by low velocities in the antipodal region (Red Sea-Gulf of Aden-East African Rift). By contrast the geoid $l=2$ pattern is dominated by geoid highs over the western Pacific subduction zones. A spherical harmonic expansion of regionalized phase velocities shows that they have $l=2$ variations similar to those of the $l_{\max }=2$ nonregionalized inversions. This means that the regionalization approach is appropriate as a first step for studying lateral heterogeneity of the earth. However, the great circle phase velocities are not sufficient by themselves to uniquely locate the lateral heterogeneity. The same is true for free oscillation data. Regions of convergence have the interesting property of being slow for short-period waves and fast, faster than shields, for long-period waves.
\end{abstract}

\section{INTRODUCTION}

To elucidate global-scale lateral heterogeneity of the earth's mantle, the phase velocity of long-period ( $\gtrsim 100 \mathrm{~s})$ surface waves over great circle paths has been measured from the phase difference of two multiple phases (e.g., $G_{2}-G_{4}$ or $R_{2}-R_{4}$ ) since the work by Satô [1958]. More recently, observations of eigenperiods of fundamental spheroidal modes have been used to study the structure of the upper mantle and transition region [Silver and Jordan, 1981; Masters et al., 1982]. The normal mode and traveling wave approaches are equivalent.

In the present paper we study the global lateral heterogeneity of the upper mantle by using the classical Fourier transform method [Satô, 1958; Brine et al., 1961]. We measured the phase velocities of fundamental-mode Love and Rayleigh waves for about 200 and 250 great circle paths. The period ranges from 100 to $330 \mathrm{~s}$. These data are interpreted in terms of regional variations of phase velocity. Our data overlap the period range of normal mode studies [Masters et al., 1982].

Backus [1964] and Zharkov and Lyubimov [1970], however, proved that observations of great circle phase velocity or, equivalently, the normal mode periods are insensitive to the odd harmonics of the aspherical heterogeneity of the earth. The regionalization approach to the interpretation of great circle phase velocities [Toksöz and Anderson, 1966] that we adopt in this paper is a method for extrapolating the odd

\footnotetext{
${ }^{1}$ Now at Research Center for Earthquake Prediction, Faculty of Science, Hokkaido University.

Copyright 1983 by the American Geophysical Union.
}

Paper number 3B1469.

0148-0227/83/003B-1469\$05.00 harmonics from the information about the even harmonics by using some external information about lateral heterogeneity (e.g., surface tectonics). This well-known fact motivated our previous study [Nakanishi and Anderson, 1982] and part 2 of this study (I. Nakanishi and D. L. Anderson, unpublished manuscript, 1983), in which we measure the surface wave velocities between earthquakes and stations incorporating information about source mechanism and finiteness.

\section{Data Set}

We analyzed digital seismograms from 25 large $\left(M_{s} \gtrsim 6.5\right)$ earthquakes recorded at IDA (International Deployment of Accelerographs) [Agnew et al., 1976] and GDSN (Global Digital Seismograph Network) during 1980. Figure 1 shows the locations of the 25 earthquakes and the IDA and GDSN stations. We use the same map projection throughout this paper. We used NEIS (National Earthquake Information Service) locations and origin times in this study. These are listed in Table 1 .

We processed wavelet pairs $G_{2}-G_{4}, G_{3}-G_{5}, R_{2}-R_{4}, R_{3}-R_{5}$, and $R_{4}-R_{6}$ to obtain the great circle phase velocities. The numbers of these pairs are $163,35,188,64$, and 1 , respectively. The choice of pairs was based on visual observation of the seismograms plotted from the original magnetic tapes. A general criterion for data selection was to use $G_{2}-G_{4}$ and $R_{2}-R_{4}$ for each earthquake-station pair. We used $G_{3}-G_{5}$ or $R_{3}-R_{5}$ only when its signal-to-noise ratio is superior to that of $G_{2}-G_{4}$ or $R_{2}-R_{4}$.

For Love waves we used long-period horizontal component seismograms from GDSN stations. The original long-period GDSN seismograms have a digitization interval of $1 \mathrm{~s}$. We applied a low-pass cosine filter with a cutoff period of $30 \mathrm{~s}$ and 


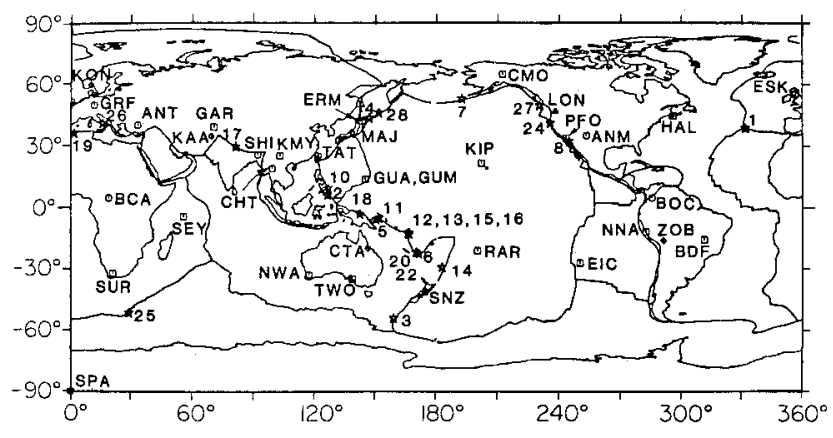

Fig. 1. Locations of epicenters (stars), IDA stations (squares), SRO stations (circles), ASRO stations (diamonds), and DWWSSN stations (triangles).

resampled at an interval of $10 \mathrm{~s}$. The resampled seismograms are used in the following data analyses. We rotated the seismograms to obtain the transverse component, taking into account the difference in response of the two components. The transverse components were windowed with fixed group velocities of 4.2 and $4.5 \mathrm{~km} / \mathrm{s}$ in most cases. In a few cases the group velocity window was $4.25-4.5 \mathrm{~km} / \mathrm{s}$ or $4.3-4.5 \mathrm{~km} / \mathrm{s}$. Figure $2 a$ shows the 198 great circle paths used for the Love wave analysis. The number of wave-pairs used for each earthquake is summarized in Table 2.

For Rayleigh waves we used long-period vertical component seismograms from IDA and GDSN stations. The IDA seismograms have a digital interval of 10 or $20 \mathrm{~s}$. The GDSN seismograms were resampled at an interval of $10 \mathrm{~s}$. The vertical component seismograms were windowed with fixed group velocities of 3.35 and $4.0 \mathrm{~km} / \mathrm{s}$ in most cases. In a few cases the group velocity window was narrowed to $3.4-3.8 \mathrm{~km} / \mathrm{s}$. Figure $2 b$ shows 253 great circle paths used for the Rayleigh wave analysis. The number of wave pairs used for each earthquake is summarized in Table 2.
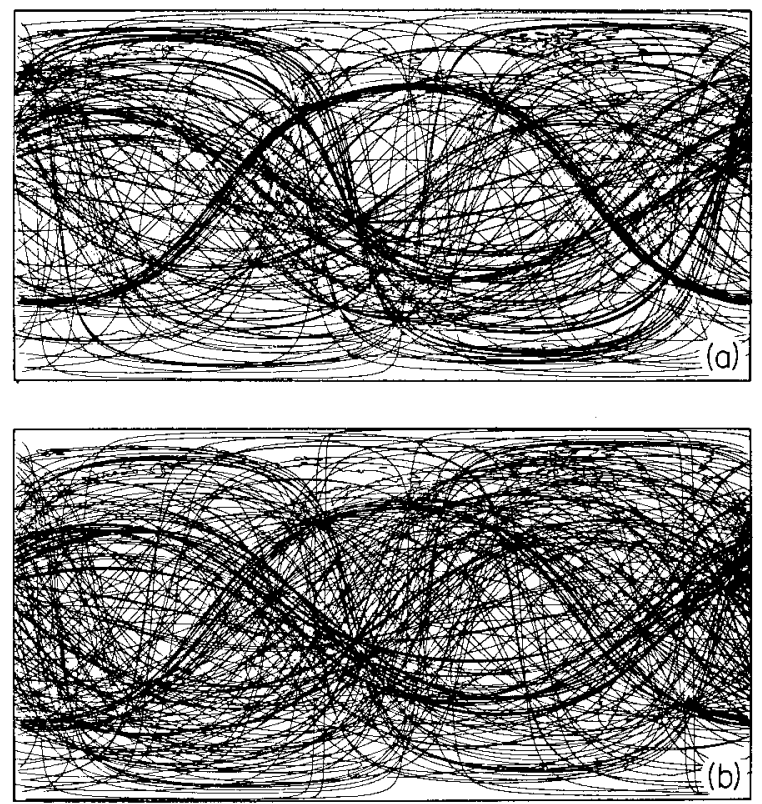

Fig. 2. Great circle paths connecting earthquakes and stations used for the great circle phase velocity measurement. The same map projection as Figure 1: (a) Love waves, (b) Rayleigh waves.

\section{Great Circle Phase Velocity Measurement}

\section{Method}

Many authors have applied this method to the measurement of phase velocity of long-period surface waves since the paper by Sato [1958]. Brune et al. [1961] made an important correction-the so-called polar phase shift correction-to Satô's method. Using this method, we can calculate accurate surface wave phase velocities for complete great circle transits without information about source mechanism, finiteness, and

TABLE 1. List of Earthquakes (in 1980) Used

\begin{tabular}{clcccccl}
\hline Example & \multicolumn{1}{c}{ Date } & Time & $\begin{array}{c}\text { Latitude, } \\
\text { deg }\end{array}$ & $\begin{array}{c}\text { Longitude, } \\
\text { deg }\end{array}$ & $\begin{array}{c}\text { Depth, } \\
\mathrm{km}\end{array}$ & $M_{S}$ & \multicolumn{1}{c}{ Region } \\
\hline 1 & January 1 & $1642: 49.0$ & $38.815 \mathrm{~N}$ & $27.780 \mathrm{~W}$ & 10 & 6.7 & Azores \\
2 & January 2 & $2058: 44.2$ & $5.984 \mathrm{~N}$ & $126.188 \mathrm{E}$ & 63 & & Mindanao \\
3 & February 7 & $1049: 16.0$ & $54.158 \mathrm{~S}$ & $158.890 \mathrm{E}$ & 10 & 6.5 & Macquarie Island \\
4 & February 23 & $0551: 03.2$ & $43.530 \mathrm{~N}$ & $146.753 \mathrm{E}$ & 44 & 7.0 & Kurile Islands \\
5 & February 27 & $2117: 20.2$ & $6.017 \mathrm{~S}$ & $150.189 \mathrm{E}$ & 53 & 6.6 & New Britain \\
6 & March 8 & $2212: 10.3$ & $22.673 \mathrm{~S}$ & $171.357 \mathrm{E}$ & 38 & 6.7 & Loyalty Island \\
7 & March 24 & $0359: 51.3$ & $52.969 \mathrm{~N}$ & $167.670 \mathrm{~W}$ & 33 & 6.9 & Fox Island \\
8 & June 9 & $0328: 18.9$ & $32.220 \mathrm{~N}$ & $114.985 \mathrm{~W}$ & 5 & 6.4 & California-Mexico border \\
10 & June 18 & $1714: 54.5$ & $9.475 \mathrm{~N}$ & $126.657 \mathrm{E}$ & 54 & 6.8 & Mindanao \\
11 & June 25 & $2318: 20.4$ & $5.233 \mathrm{~S}$ & $151.686 \mathrm{E}$ & 49 & 6.5 & New Britain \\
12 & July 8 & $2319: 19.8$ & $12.410 \mathrm{~S}$ & $166.381 \mathrm{E}$ & 33 & 7.5 & Santa Cruz \\
13 & July 9 & $2056: 53.2$ & $12.689 \mathrm{~S}$ & $166.004 \mathrm{E}$ & 33 & 6.7 & Santa Cruz \\
14 & July 14 & $1615: 01.7$ & $29.273 \mathrm{~S}$ & $177.154 \mathrm{~W}$ & 49 & 6.6 & Kermadec \\
15 & July 17 & $1942: 23.2$ & $12.525 \mathrm{~S}$ & $165.916 \mathrm{E}$ & 33 & 7.9 & Santa Cruz \\
16 & July 29 & $0311: 56.3$ & $13.101 \mathrm{~S}$ & $166.338 \mathrm{E}$ & 48 & 6.7 & Vanuatu Island \\
17 & July 29 & $1458: 40.8$ & $29.598 \mathrm{~N}$ & $81.092 \mathrm{E}$ & 18 & 6.5 & Nepal \\
18 & September 26 & $1520: 37.1$ & $3.225 \mathrm{~S}$ & $142.237 \mathrm{E}$ & 33 & 6.5 & Papua \\
19 & October 10 & $1225: 23.5$ & $36.195 \mathrm{~N}$ & $1.354 \mathrm{E}$ & 10 & 7.3 & Algeria \\
20 & October 24 & $0325: 34.4$ & $21.989 \mathrm{~S}$ & $170.165 \mathrm{E}$ & 33 & 6.7 & Loyalty Island \\
22 & October 25 & $1100: 05.1$ & $21.890 \mathrm{~S}$ & $169.853 \mathrm{E}$ & 33 & 7.2 & Loyalty Island \\
24 & November 8 & $1027: 34.0$ & $41.117 \mathrm{~N}$ & $124.253 \mathrm{~W}$ & 19 & 7.2 & Northern California \\
25 & November 11 & $1036: 58.2$ & $51.422 \mathrm{~S}$ & $28.796 \mathrm{E}$ & 10 & 6.7 & South Africa \\
26 & November 23 & $1834: 53.8$ & $40.914 \mathrm{~N}$ & $15.366 \mathrm{E}$ & 10 & 6.9 & Italy \\
27 & December 17 & $1621: 58.8$ & $49.479 \mathrm{~N}$ & $129.496 \mathrm{~W}$ & 10 & 6.8 & Vancouver Island \\
28 & December 31 & $1032: 11.0$ & $46.060 \mathrm{~N}$ & $151.453 \mathrm{E}$ & 33 & 6.5 & Kurile Islands \\
\hline
\end{tabular}

NEIS (National Earthquake Information Service) locations and origin times are used. 
TABLE 2. Number of Multiple Wave Pairs

\begin{tabular}{|c|c|c|c|}
\hline & Love & $\begin{array}{c}\text { Rayleigh, } \\
\text { GDSN }\end{array}$ & $\begin{array}{c}\text { Rayleigh, } \\
\text { IDA }\end{array}$ \\
\hline A1 & 10 & 4 & 3 \\
\hline M2 & & & 3 \\
\hline M3 & 15 & 6 & 4 \\
\hline K4 & 9 & 9 & 8 \\
\hline N5 & & & 6 \\
\hline L6 & & & 7 \\
\hline F7 & 10 & 6 & 5 \\
\hline $\mathrm{C} 8$ & 9 & 1 & 3 \\
\hline M10 & 14 & 7 & 9 \\
\hline N11 & & & 4 \\
\hline S12 & 13 & 6 & 7 \\
\hline $\mathrm{S} 13$ & & & 5 \\
\hline K14 & 8 & & 1 \\
\hline \$15 & & & 7 \\
\hline V16 & 11 & 4 & 6 \\
\hline N17 & 6 & 4 & 4 \\
\hline P18 & 8 & 3 & 4 \\
\hline A19 & 9 & 10 & 6 \\
\hline L20 & 11 & 7 & 6 \\
\hline L22 & 12 & 8 & 7 \\
\hline C24 & 11 & 13 & 6 \\
\hline A 25 & 13 & 8 & 4 \\
\hline I26 & 11 & 4 & 9 \\
\hline V27 & 11 & 12 & 5 \\
\hline K28 & 7 & 7 & 5 \\
\hline Sum & 198 & 119 & 134 \\
\hline
\end{tabular}

instrumental response. Thus this method has attracted seismologists for many years. Interpretation of the great circle phase velocities will be discussed later.

In this study the great circle phase velocity is calculated from a wave pair $G_{i}-G_{i+2}$ or $R_{i}-R_{i+2}$ by using

$$
C(T)=\frac{L}{\left(t_{i+2}-t_{i}\right)+T\left[\frac{\phi_{i}-\phi_{i+2}}{2 \pi}+\frac{1}{2}+N\right]}
$$

where $T$ is the period, $L$ is the length of the great circle path passing through an earthquake epicenter and a recording station, $t_{i}$ is the starting time of the group-velocity-windowed seismogram of the surface wave of order $i, \phi_{i}$ is the Fourier phase at period $T$ measured with respect to the starting time $t_{i}$, the factor of $1 / 2$ comes from polar phase shifts at the epicenter and its antipode, and $N$ is an integer which arises from the multivalued nature of Fourier phase and which is determined so that measured phase velocities at long periods connect smoothly with phase velocities calculated from the eigenperiods of the earth. We used the geometrical flattening of the earth's figure to calculate $L$. We assumed equatorial radius $a$ and polar radius $b$ to be 6378.388 and $6356.912 \mathrm{~km}$, respectively. These values are equivalent to the geometrical flattening $f_{g}=1 / 297.001$ and a mean radius $R_{0}=\sqrt[3]{a^{2} b}=6371.221$ $\mathrm{km}$. We use this value as the mean radius throughout this paper. We used Rudoe's formula to calculate the length of the geodesic around the geoellipsoid of revolution [Bomford, 1962; Maruyama, 1967]. This formula is equivalent to

$$
L(\Theta)=2 \pi R_{0}\left[1-\frac{1}{6} f_{g}\left(1-3 \cos ^{2} \Theta\right)\right]
$$

correct to the first order in $f_{g}$, where $\Theta$ is the colatitude of the positive pole of the directed great circle path. The frequency dependence of the ellipticity, or path length, advocated by Dahlen [1975; see Dziewonski and Sailor, 1976; Dahlen, 1976] will be allowed for when interpreting the $l=2$ harmonics of the lateral heterogeneity, where a hydrostatic flattening $f_{h}=$ 1/299.627 [Nakiboglu, 1982] will be used. We used Goertzel's algorithm to calculate the Fourier phases $\phi_{i}$ and $\phi_{i+2}$.

\section{Effect of Higher Mode Contamination}

We need to analyze the effect of higher Love-mode contamination on the measurement of phase velocities of fundamental-mode Love waves because we do not apply any spatial filters to separate higher modes from fundamental modes. Thatcher and Brune [1969], Boore [1969], and Schlue [1975] made a simple estimation of the error due to the interference for small-distance phase velocity measurements. Dziewonski et al. [1972] suggested possible contamination by higher modes, even at long periods ( 170 to $350 \mathrm{~s})$, because of a discrepancy among several sets of average Love wave phase velocities. To eliminate higher-mode interference, we can apply a spatial filter by using a closely spaced array. However, such an array is not available for the study of global-scale seismic structure. As Figure 1 shows, IDA and GDSN stations are too sparsely located to use for spatial filtering.

We follow Thatcher and Brune [1969] and make an error analysis of the higher-mode interference. Here we consider the effect of the first higher mode on the great circle phase velocity measurement of the fundamental mode. We use (1) to calculate the phase velocity. In this error analysis, $\left(t_{i+2}-t_{i}\right)$ is taken to be zero, and a spherical earth is assumed. Let us consider the case that we process $\left(G_{i}{ }^{0}+G_{i}{ }^{1}\right)$ and $\left(G_{i+2}{ }^{0}\right.$ $\left.+G_{i+2}{ }^{1}\right)$ as $\left(G_{i}^{0}\right)$ and $\left(G_{i+2}{ }^{0}\right)$, respectively, where the superscripts 0 and 1 represent the fundamental and the first higher modes. In the great circle phase velocity measurement we can ignore the initial phase at the source, the source finiteness, and the instrumental response. We write [Thatcher and Brune, 1969]

$$
\phi_{i}=-\tan ^{-1}\left[\frac{\sin \kappa_{0} \Delta+\lambda(T) \sin \kappa_{1} \Delta}{\cos \kappa_{0} \Delta+\lambda(T) \cos \kappa_{1} \Delta}\right]+\frac{(i-1)}{2} \pi
$$

and

$$
\begin{array}{r}
\phi_{i+2}=-\tan ^{-1}\left[\frac{\sin \kappa_{0}(\Delta+L)+\lambda(T) \sin \kappa_{1}(\Delta+L)}{\cos \kappa_{0}(\Delta+L)+\lambda(T) \cos \kappa_{1}(\Delta+L)}\right] \\
+\frac{(i+1)}{2} \pi
\end{array}
$$

where $\Delta$ is the distance that $\left(G_{i}{ }^{0}+G_{i}{ }^{1}\right)$ propagates from an epicenter to the station, $L$ is the length of the great circle of the spherical earth, $\lambda(T)$ is the amplitude ratio of $G^{1}$ to $G^{0}, \kappa$ is the wave number for a given period $T$, and relative attenuation between $G^{0}$ and $G^{1}$ for the one great circle is assumed to be zero. The second terms in (3) and (4) are polar phase shifts. Since $C(T)$ for $\lambda(T)=0$ is equal to the phase velocity of the fundamental mode, the phase velocity error due to the interference is

$$
\delta C=C(\lambda \neq 0)-C(\lambda=0)
$$

We made a numerical estimation of the interference error by using (1), (3), (4), and (5). We consider wave pairs $\left(G_{2}{ }^{0}+\right.$ $\left.G_{2}{ }^{1}\right)-\left(G_{4}{ }^{0}+G_{4}{ }^{1}\right)$ and $\left(G_{3}{ }^{0}+G_{3}{ }^{1}\right)-\left(G_{5}{ }^{0}+G_{5}{ }^{1}\right)$ observed at stations located at minor arc distances of $30^{\circ}, 60^{\circ}, 90^{\circ}, 120^{\circ}$, and $150^{\circ}$. The errors are estimated for periods of $100,110,120$, 130 , and $140 \mathrm{~s}$. We use the phase velocities of the fundamental and the first higher mode for the oceanic and shield structure calculated by Anderson and Harkrider [1968]. We assume $\lambda(T)$ to be 0.5 for all $G^{1}$. The calculation results are summarized as 


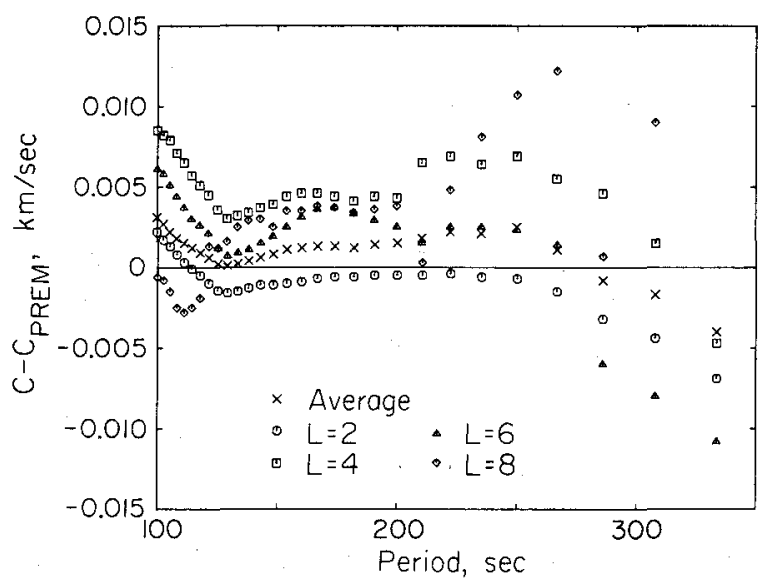

Fig. 3. Spherical average Love wave phase velocities. Deviations from Earth model PREM are shown. Five spherical averages obtained in the following ways are shown: cross-an arithmetic average of the observed great circle phase slownesses; circle-spherically averaged phase velocity calculated from the coefficient $A_{00}\left(C_{00}=\right.$ $1 / A_{00}$ ) obtained by $L=2$ inversion of the great circle phase velocities; open square $-C_{00}$ from $L=4$ inversion; open triangle $-C_{00}$ from $L=8$ inversion.

follows. A maximum $\delta C$ of $0.012 \mathrm{~km} / \mathrm{s}$ is obtained for $G_{3}-G_{5}$ at $140 \mathrm{~s}$ observed at $\Delta=60^{\circ}$ by using a shield structure. The error, however, is generally smaller than $0.01 \mathrm{~km} / \mathrm{s}$ and averages about $0.004 \mathrm{~km} / \mathrm{s}$. The error does not show coherence among periods. As will be seen in the following sections, the expected errors seem to be much smaller than the observed long-wavelength variations of Love wave phase velocities. The incoherence of $\delta C$ among different periods suggests that the higher-mode interference does not cause a systematic bias in the observed phase velocities but contributes to the scatter of the observations. This is the same error estimate

TABLE 3. Average Love Wave Great Circle Phase Velocity

\begin{tabular}{cccc}
\hline Period, $\mathrm{s}$ & $C, \mathrm{~km} / \mathrm{s}$ & $C$ - $C_{\text {PREM }}, \mathrm{km} / \mathrm{s}$ & $\sigma C, \mathrm{~km} / \mathrm{s}$ \\
\hline 333.33 & 5.3319 & -0.0040 & 0.0270 \\
307.69 & 5.2518 & -0.0017 & 0.0261 \\
285.71 & 5.1825 & -0.0008 & 0.0237 \\
266.67 & 5.1243 & 0.0011 & 0.0231 \\
250.00 & 5.0733 & 0.0025 & 0.0229 \\
235.29 & 5.0276 & 0.0021 & 0.0231 \\
222.22 & 4.9878 & 0.0022 & 0.0227 \\
210.53 & 4.9522 & 0.0018 & 0.0233 \\
200.00 & 4.9206 & 0.0015 & 0.0234 \\
190.48 & 4.8926 & 0.0014 & 0.0236 \\
181.82 & 4.8675 & 0.0012 & 0.0242 \\
173.91 & 4.8447 & 0.0013 & 0.0243 \\
166.67 & 4.8243 & 0.0013 & 0.0262 \\
160.00 & 4.8054 & 0.0012 & 0.0266 \\
153.85 & 4.7884 & 0.0011 & 0.0269 \\
148.15 & 4.7722 & 0.0008 & 0.0272 \\
142.86 & 4.7575 & 0.0006 & 0.0273 \\
137.93 & 4.7439 & 0.0004 & 0.0281 \\
133.33 & 4.7314 & 0.0002 & 0.0278 \\
129.03 & 4.7197 & 0.0001 & 0.0283 \\
125.00 & 4.7089 & 0.0002 & 0.0287 \\
121.21 & 4.6991 & 0.0006 & 0.0289 \\
117.65 & 4.6901 & 0.0009 & 0.0288 \\
114.29 & 4.6812 & 0.0012 & 0.0288 \\
111.11 & 4.6729 & 0.0015 & 0.0289 \\
108.11 & 4.6653 & 0.0018 & 0.0291 \\
105.26 & 4.6581 & 0.0022 & 0.0290 \\
102.56 & 4.6515 & 0.0027 & 0.0301 \\
100.00 & 4.6451 & 0.0031 & 0.0296 \\
\hline
\end{tabular}

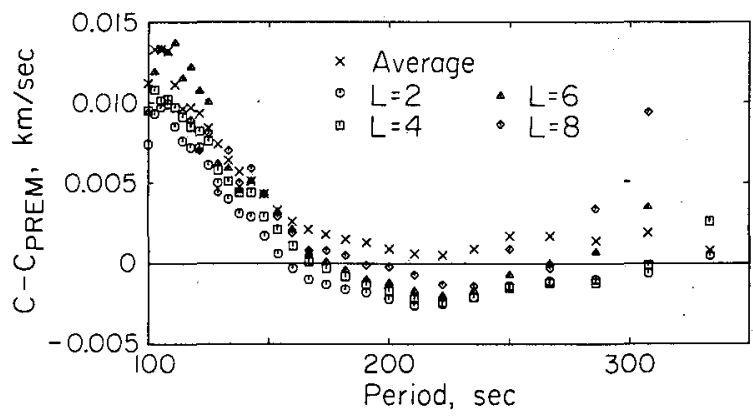

Fig. 4. Spherical average Rayleigh wave phase velocities. The conventions are the same as in Figure 3.

obtained by Boore [1969] and Schlue [1975] for two-station and single-station phase velocity measurements, respectively.

\section{Measurement Results}

Great circle phase velocities are determined for periods between 100 and $330 \mathrm{~s}$ for the great circle paths shown in Figure 2. Using data from both IDA and GDSN stations, we have a very dense path coverage over the earth's surface. Figure 3 and Table 3 show averaged Love wave phase velocities and their standard deviations. Deviations from Earth model PREM [Dziewonski and Anderson, 1981] are less than 0.005 $\mathrm{km} / \mathrm{s}$ in the whole period range. The averaged Rayleigh wave phase velocities are shown in Figure 4 and Table 4. The observations show large deviations from PREM at periods below $150 \mathrm{~s}$. For periods greater than $150 \mathrm{~s}$ the differences are less than $0.004 \mathrm{~km} / \mathrm{s}$.

A quick way to look at regional variations of phase velocities is to examine the azimuthal variation for each earthquake. We made azimuthal plots for all observations. Here we show results for two earthquakes. One is the Santa Cruz Islands

TABLE 4. Average Rayleigh Wave Great Circle Phase Velocity

\begin{tabular}{cccc}
\hline Period, $\mathrm{s}$ & $C, \mathrm{~km} / \mathrm{s}$ & $C$ - $C_{\text {PREM }}, \mathrm{km} / \mathrm{s}$ & $\sigma C, \mathrm{~km} / \mathrm{s}$ \\
\hline 333.33 & 5.5280 & 0.0008 & 0.0153 \\
307.69 & 5.3488 & 0.0019 & 0.0181 \\
285.71 & 5.1859 & 0.0014 & 0.0202 \\
266.67 & 5.0434 & 0.0017 & 0.0208 \\
250.00 & 4.9198 & 0.0017 & 0.0186 \\
235.29 & 4.8132 & 0.0009 & 0.0181 \\
222.22 & 4.7219 & 0.0005 & 0.0179 \\
210.53 & 4.6442 & 0.0006 & 0.0177 \\
200.00 & 4.5774 & 0.0009 & 0.0180 \\
190.48 & 4.5198 & 0.0013 & 0.0172 \\
181.82 & 4.4693 & 0.0015 & 0.0179 \\
173.91 & 4.4251 & 0.0018 & 0.0171 \\
166.67 & 4.3861 & 0.0021 & 0.0176 \\
160.00 & 4.3513 & 0.0026 & 0.0172 \\
153.85 & 4.3212 & 0.0033 & 0.0173 \\
148.15 & 4.2942 & 0.0043 & 0.0177 \\
142.86 & 4.2702 & 0.0051 & 0.0167 \\
137.93 & 4.2477 & 0.0057 & 0.0162 \\
133.33 & 4.2279 & 0.0064 & 0.0155 \\
129.03 & 4.2099 & 0.0074 & 0.0165 \\
125.00 & 4.1935 & 0.0084 & 0.0160 \\
121.21 & 4.1785 & 0.0093 & 0.0159 \\
117.65 & 4.1646 & 0.0097 & 0.0152 \\
114.29 & 4.1511 & 0.0096 & 0.0170 \\
111.11 & 4.1402 & 0.0111 & 0.0179 \\
108.11 & 4.1309 & 0.0132 & 0.0174 \\
105.26 & 4.1205 & 0.0133 & 0.0173 \\
102.56 & 4.1106 & 0.0133 & 0.0182 \\
100.00 & 4.0994 & 0.0112 & 0.0191 \\
\hline
\end{tabular}




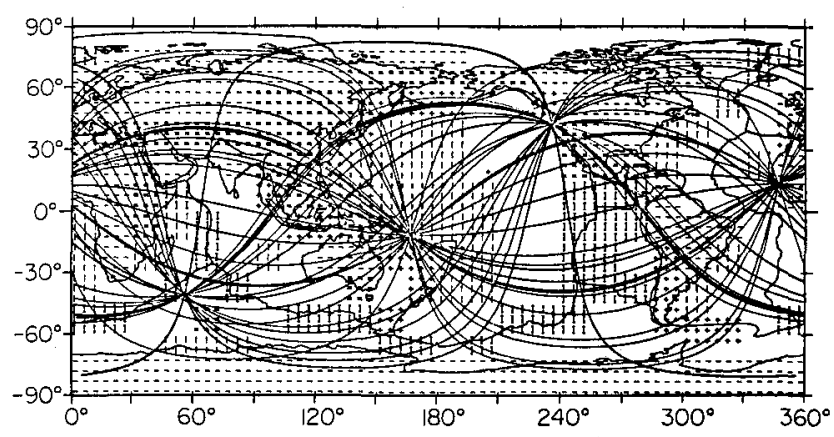

Fig. 5. Surface wave paths for the observations in Figures 6-9. Convergence points correspond to epicenters or antipodes. Okal's [1977] regionalization model is also shown. The grid size is $5^{\circ} \times 5^{\circ}$ : - , shield (region $\mathbf{S}$ ); $=$, mountainous region (region $\mathbf{M}$ ); + , trench and marginal sea (region T); $I$, ocean 0-30 m.y. old (region D); blank, ocean 30-80 m.y. old (region C); |, ocean 80-135 m.y. old (region B); :, ocean older than $135 \mathrm{~m} . \mathrm{y}$. old (region A).

earthquake (event 12), and the other is the Eureka earthquake (event 24). Figure 5 shows the surface wave ray paths for which we measured the phase velocities of Love or Rayleigh waves. Also shown in the figure is Okal's [1977] regionalization model. Convergence points in the southwest Pacific and in western North America are the epicenters of the Santa Cruz Islands and Eureka earthquakes. Figures 6 and 7 show azimuthal variations of Love wave phase velocities. Figures 8 and 9 are for Rayleigh waves. Let us examine Love wave phase velocities from the Eureka earthquake (Figure 7). The observations exhibit the lowest phase velocities in the

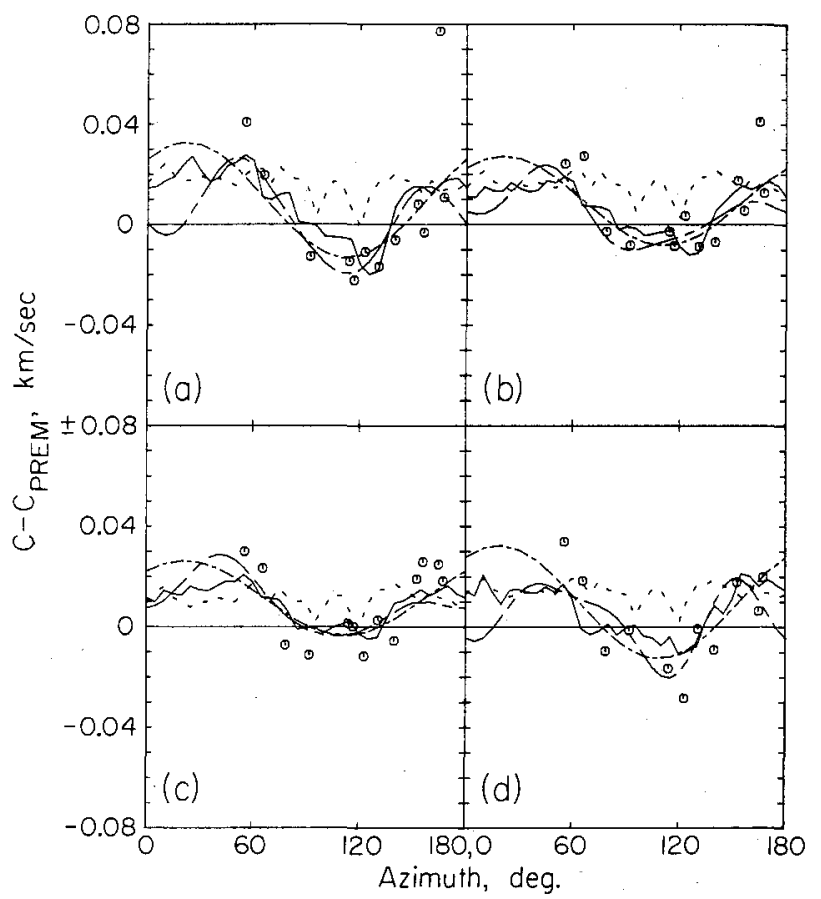

Fig. 6. Azimuthal variations of Love wave phase velocities determined from the Santa Cruz Islands earthquake (event 12). Deviations from model PREM are shown. The azimuth is compressed to the range from $0^{\circ}$ to $180^{\circ}$. For example, a station whose earthquake-tostation azimuth is $240^{\circ}$ is plotted at an azimuth of $60^{\circ}$. Open circles indicate the observations. The broken and the solid lines are calculated from the regionalized phase velocities of Kanamori [1970] and those obtained in this study. Fine and rough chain lines are calculated from the results of $L=2$ and $L=6$ even-harmonics inversion, respectively: (a) $148 \mathrm{~s},(b) 200 \mathrm{~s},(c) 250 \mathrm{~s},(d) 307 \mathrm{~s}$.

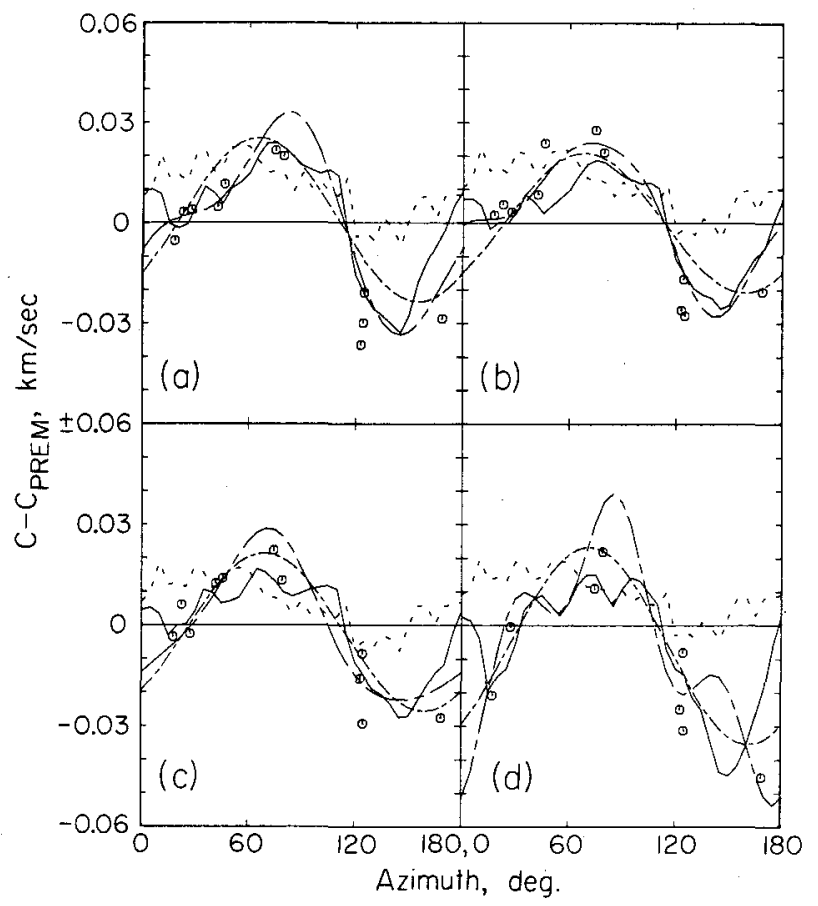

Fig. 7. Azimuthal variations of Love wave phase velocities determined from the Eureka earthquake (event 24). See Figure 6 for conventions.

azimuths around $120^{\circ}$ and $180^{\circ}$. Figure 5 shows that the azimuth window from $120^{\circ}$ to $180^{\circ}$ involves large portions of tectonically active regions, such as young ocean in the southeast Pacific, Phanerozoic orogenic and magmatic belts in

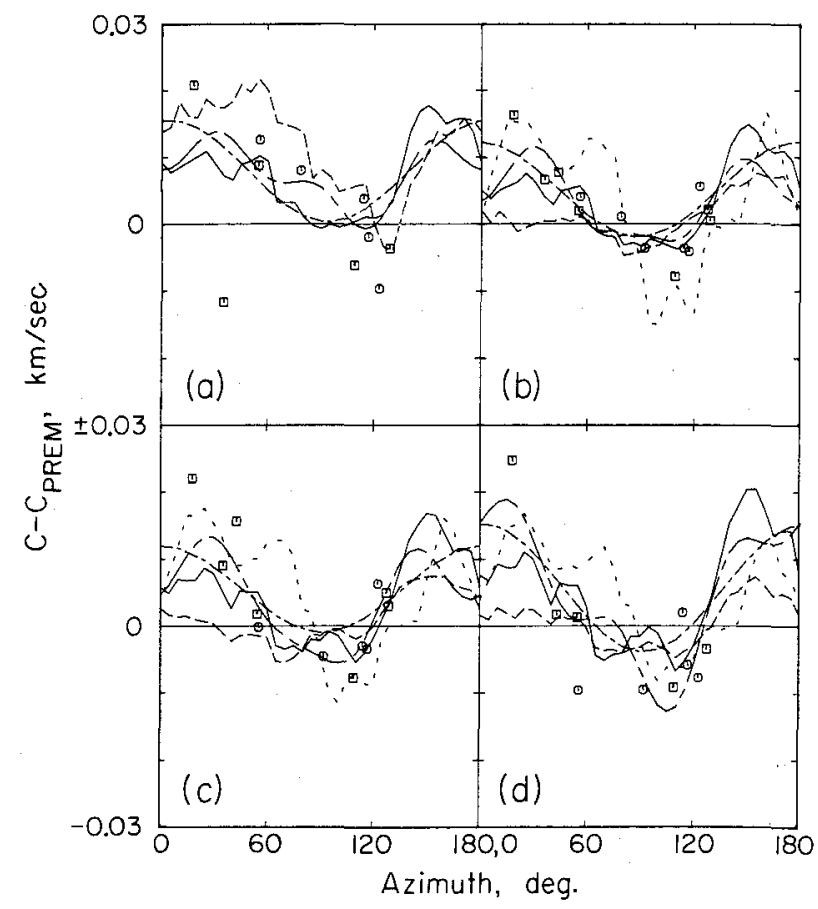

Fig. 8. Azimuthal variations of Rayleigh wave phase velocities determined from the Santa Cruz earthquake. Open squares and open circles represent observations from IDA and GDSN stations, respectively. Fine and rough broken lines are calculated values from the regionalized phase velocities of Dziewonski and Steim [1982] and Souriau and Souriau [1983]. Solid line is calculated from the regionalized phase velocities obtained in this study. Fine and rough chain lines are calculated from the results of $L=2$ and $L=6$ inversion, respectively. Other conventions are same as in Figure 6. 


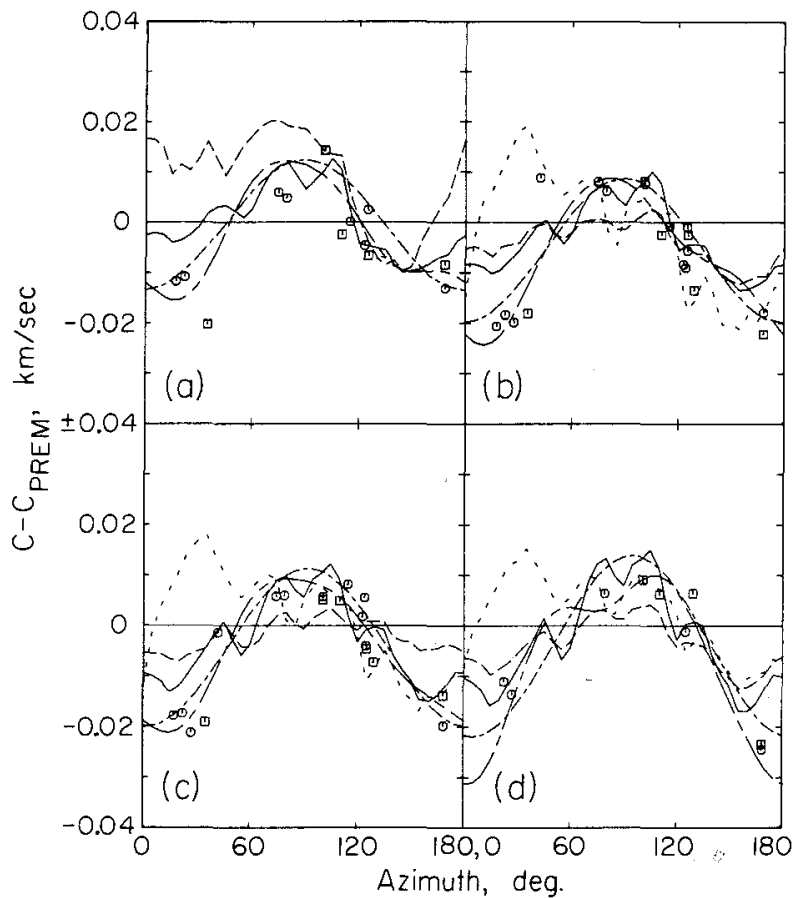

Fig. 9. Azimuthal variations of Rayleigh wave phase velocities determined from the Eureka earthquake. See Figure 8 for conventions.

western North America and eastern Eurasia, and young ocean in the Indian Sea. The observations in Figures 6, 8, and 9 also show correlation with surface geology. These correlations between observed phase velocities and surface geology suggest that regionalizing surface wave phase velocities may be fruitful, even for the longer periods. This approach will be used later in this paper. However, what we have to keep in mind is that we cannot locate uniquely the heterogeneity from great circle measurements [Backus, 1964]. Therefore, very detailed regionalized models of the earth are inappropriate for this kind of data.

\section{Estimation Methods of Geographical Distribution of Surface Wave Velocities}

We assume that the apparent phase slowness between an earthquake source and a seismic station is the average of phase slowness along the great circle path connecting the two points [Toksöz and Anderson, 1966; Knopoff, 1969]. Thus, the phase delay due to propagation along the surface wave path can be written

$$
t_{E S}(\omega)=\int_{E}^{S} \frac{d s}{C(\omega, \Omega)}
$$

where $t_{E S}(\omega)$ is the phase delay, which has a dimension of time, of surface wave of frequency $\omega$ between an earthquake $(E)$ and a station $(S)$, and the phase velocity $C$ is a function of frequency $\omega$ and the position represented by $\Omega=(\theta, \phi)$.

We expand the phase slowness $1 / C(\omega, \Omega)$ in terms of spherical harmonics:

$$
1 / C(\omega, \Omega)=\sum_{l=0}^{\infty} \sum_{m=-l}^{m=l} s_{l m}(\omega) Y_{l m}(\Omega)
$$

where $Y_{l m}(\Omega)$ is fully normalized spherical harmonics, and the following convention is used:

$$
\sum_{m=-l}^{m=l} S_{l m} Y_{l m}(\Omega)=\sum_{m=0}^{l}\left(A_{l m} \cos m \phi+B_{l m} \sin m \phi\right) P_{l m}(\cos \theta)
$$

From (6) and (7) we write the observed slowness as

$$
t_{E S}=\sum_{l=0}^{\infty} \sum_{m=-l}^{m=l} s_{l m} \int_{E}^{s} Y_{l m}(\Omega) d s
$$

The most accurate measurement (in the sense that we need not correct for source mechanism, source finiteness, and instrumental response) of phase velocity can be made from the great circle measurement of phase delay. We consider the great circle integral

$$
t_{G}=\sum_{l=0}^{\infty} \sum_{m=-l}^{m=l} s_{l m} \oint Y_{l m}(\Omega) d s
$$

where $t_{G}$ is the phase delay for the great circle. According to Backus [1964],

$$
\oint Y_{l m}(\Omega) d s= \begin{cases}2 \pi R_{0} P_{l}(0) Y_{l m}(\Theta, \Phi) & l=\text { even } \\ 0 & l=\text { odd }\end{cases}
$$

where $R_{0}$ is the radius of the spherical Earth, $\Theta$ and $\Phi$ are the colatitude and longitude of the positive pole of great circle path, and $P_{l}(0)$ is the Legendre function.

As (10) and (11) show we can determine even harmonics of lateral heterogeneity from great circle phase velocities or, equivalently, free oscillation periods. This is the approach taken by Masters et al. [1982]. From (10) and (11) we have

$\frac{1}{C\left(\Theta_{i}, \Phi_{i}\right)}=\sum_{l=\text { even }}^{\infty} P_{l}(0) \sum_{m=-l}^{m=l} s_{l m} Y_{l m}\left(\Theta_{i}, \Phi_{i}\right), i=1, \ldots, N$

where $C\left(\Theta_{i}, \Phi_{i}\right)$ is the great circle phase velocity for the great circle path whose positive pole is at the colatitude $\Theta_{i}$ and the longitude $\Phi_{i}$, and $N$ is the number of the great circle phase velocities. If the spherical harmonic expansion is truncated at $l=L$ (or $l_{\mathrm{max}}$ ), the number of the coefficients $s_{l m}(l=$ even) is equal to

$$
M=1+5+\cdots+(2 L+1)=(L+1)(L+2) / 2
$$

Throughout this paper, $L$ means the maximum $l$ in the expansion. If $N \gg M$ and $\left(\Theta_{i}, \Phi_{i}\right)$ is well distributed on the earth's surface, we can determine the coefficients of the even harmonics by solving (12) in least squares sense. Masters et al. [1982] made an equivalent inversion of eigenfrequencies by assuming $L=2$ or 6 .

Equation (11) shows that the great circle phase velocity does not constrain the odd harmonics of lateral variations of phase velocity [Backus, 1964]. To avoid this difficulty, an assumption about the regional variations (regionalization model) has been made in the interpretation of great circle phase velocities [Toksöz and Anderson, 1966; Kanamori, 1970; Dziewonski, 1970; Wu, 1972; Okal, 1977; Mills, 1978; Nakanishi, 1979; Lévêque, 1980; Dziewonski and Steim, 1982; Souriau and Souriau, 1983]. We assume that the earth's surface consists of $J$ regions $R_{j}(j=1, \ldots, J)$. The regions are characterized by the functions $n_{j}$ as

$$
n_{j}(\Omega)= \begin{cases}1 & \Omega \in R_{j} \\ 0 & \Omega \notin R_{j}\end{cases}
$$

Using this regionalization, we can write $C^{-1}(\Omega)$ as

$$
1 / C(\Omega)=\sum_{j=1}^{J} C_{j}^{-1} n_{j}(\Omega)
$$



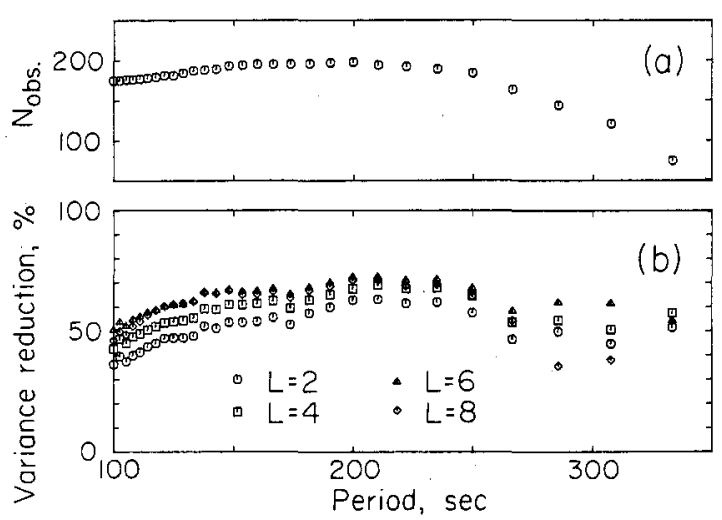

Fig. 10. Results of even-harmonics inversion of Love wave phase velocities: (a) number of observations; $(b)$ variance reduction (VR) attained by the inversion. $V R=1-\sigma_{a}{ }^{2} / \sigma_{b}{ }^{2}$, where $\sigma_{b}{ }^{2}$ and $\sigma_{a}{ }^{2}$ are the variances before and after the inversion. The results for $L \stackrel{a}{=} 2,4$, 6 , and 8 are shown.

where $C_{j}$ is a constant phase velocity of region $R_{j}$. We expand $n_{j}(\Omega)$ in spherical harmonics

$$
n_{j}(\Omega)=\sum_{l=0}^{\infty} \sum_{m=-l}^{m=l} r_{l m}^{j} Y_{l m}(\Omega)
$$

From (7), (14), and (15) we obtain

$$
\sum_{l=0}^{\infty} \sum_{m=-l}^{m=l} s_{l m} Y_{l m}(\Omega)=\sum_{j=1}^{J} C_{j}^{-1} \sum_{l=0}^{\infty} \sum_{l=-m}^{l=m} r_{l m}{ }^{j} Y_{l m}(\Omega)
$$

Thus we have

$$
s_{l m}=\sum_{j=1}^{J} C_{j}^{-1} r_{l m}^{j}
$$

This shows that we can determine not only the even harmonics but also the odd harmonics by using external information concerning the lateral heterogeneity. However, we should note that $s_{l m}(l=$ odd $)$ are not constrained from the observations but only extrapolated through the regionalization model (13). Therefore $s_{l m}(l=$ odd $)$ are sensitive to the choice of the model. From (13) and (14) we have

$$
\begin{aligned}
\oint_{\Gamma_{i}} C^{-1}(\Omega) d s & =\sum_{j=1}^{J} C_{j}^{-1} \oint_{\Gamma_{i}} n_{j}(\Omega) d s \\
& =\sum_{j=1}^{J} C_{j}{ }^{-1} L_{j}^{i} \quad i=1, \ldots, N
\end{aligned}
$$

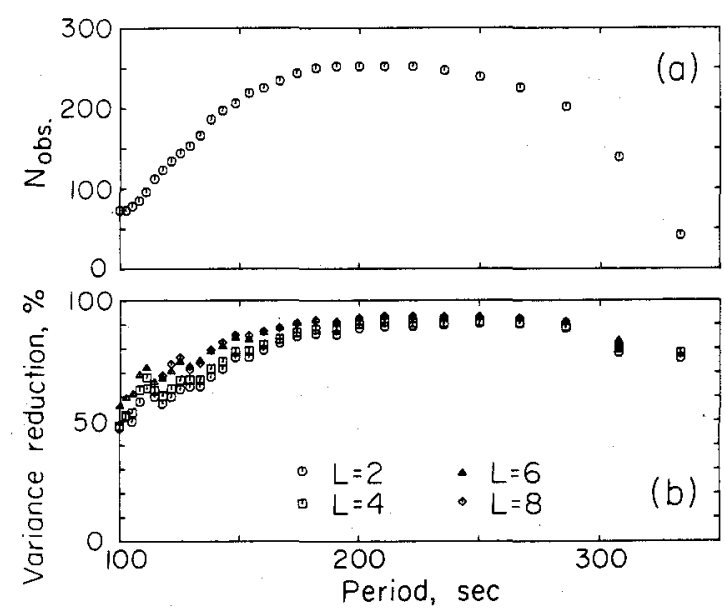

Fig. 11. Results of even-harmonics inversion of Rayleigh wave phase velocities: $(a)$ number of observations; $(b)$ variance reduction.
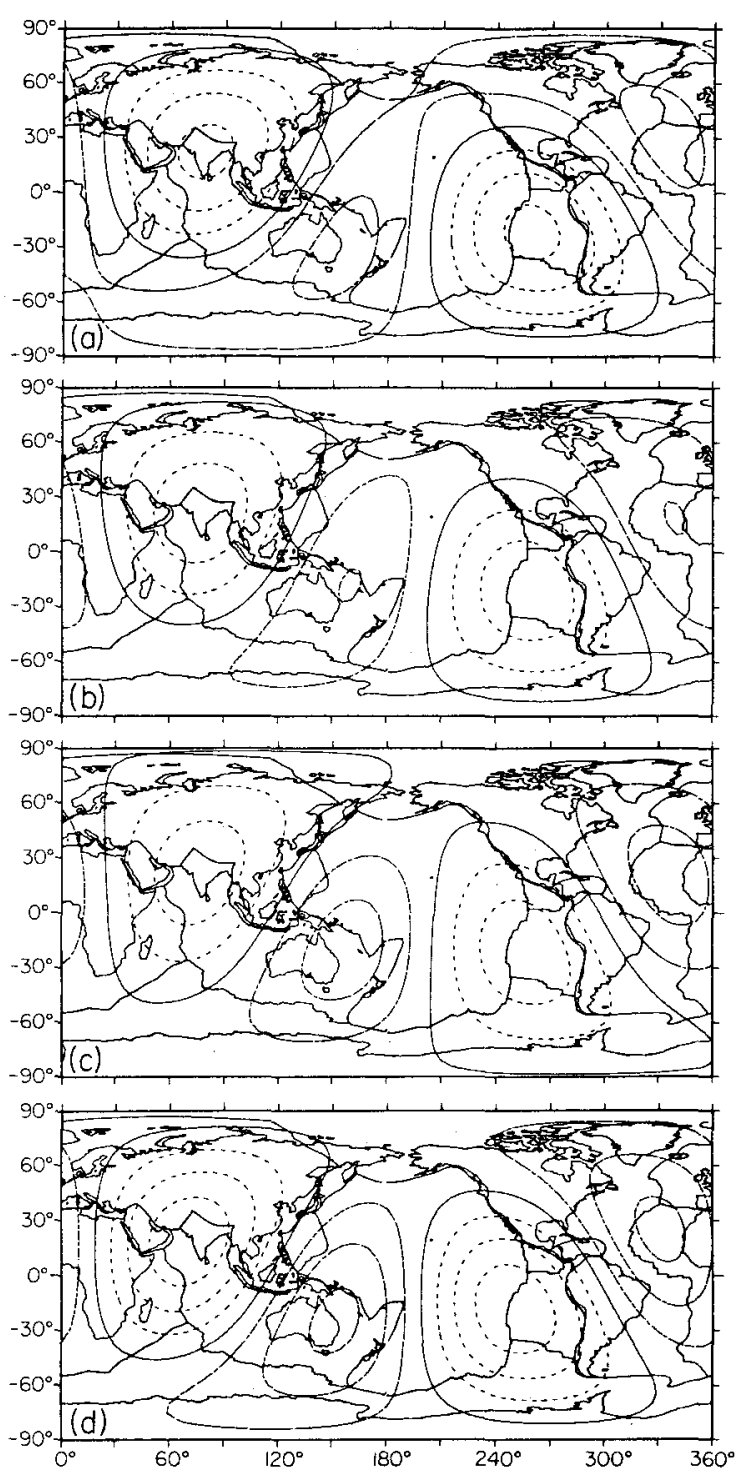

Fig. 12. Velocity distribution of Love wave phase velocities synthesized from the results of the $L=2$ inversion. The solid line corresponds to $C_{00}=1 / A_{00}$. The chain line represents velocities higher than $C_{00}$. The broken line indicates velocities lower than $C_{00}$. The contour interval is $0.02 \mathrm{~km} / \mathrm{s}:$ (a) $148 \mathrm{~s},(b) 200 \mathrm{~s},(c) 250 \mathrm{~s}$, (d) $307 \mathrm{~s}$.

where $L_{j}{ }^{i}$ is the fraction of the great circle path $\Gamma_{i}$ which lies within each region $R_{j}$, and $N$ is the number of the great circle paths. Solving (18), we can determine the pure-path phase velocity for each region $R_{j}$.

The great circle phase velocity data cannot fully describe the earth's lateral heterogeneity. Let us see what we can learn about the lateral heterogeneity from the incomplete (even harmonics) information. The linear inverse approach of Whaler and Gubbins [1981] can be used for this purpose. We write the estimate $\bar{s}$ of the slowness $s$ at $\Omega_{0}$ as a linear combination of $s_{l m}$

$$
\bar{s}\left(\Omega_{0}\right)=\sum_{l=0}^{L} \sum_{m=-l}^{m=l} q_{l m}\left(\Omega_{0}\right) s_{l m}
$$

where $s(\Omega)=1 / C(\Omega)$. With the use of the orthogonality property of spherical harmonics, we rewrite this equation

$$
\widetilde{s}\left(\Omega_{0}\right)=\oint A\left(\Omega ; \Omega_{0}\right) s(\Omega) d \Omega
$$



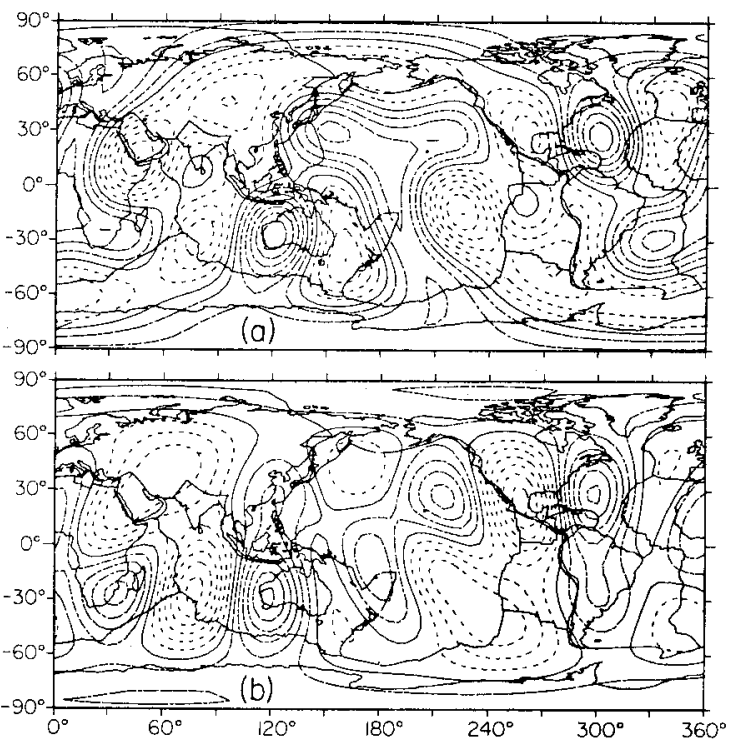

Fig. 13. Distribution of Love wave phase velocities synthesized from the results of the $L=6$ inversion. Conventions same as in Figure 12: (a) $148 \mathrm{~s},(b) 250 \mathrm{~s}$

where

$$
A\left(\Omega ; \Omega_{0}\right)=\frac{1}{4 \pi} \sum_{l=0}^{L} \sum_{m=-l}^{m=l} q_{l m} Y_{l m}
$$

Whaler and Gubbins choose $q_{l m}$ so as to make the averaging function $A\left(\Omega ; \Omega_{0}\right)$ peak near the point $\Omega_{0}$ and be small elsewhere. The averaging function for the fully normalized spherical harmonics is found to be

$$
A\left(\Omega ; \Omega_{0}\right)=\frac{1}{4 \pi} \sum_{l=0}^{L} \sqrt{2 l+1} P_{l}(\cos \gamma)
$$

where $\gamma$ is the angle between the directions $\Omega$ and $\Omega_{0}$. The case we consider is $l=$ even. If we use only $l=2$ terms of the expansion, we have

$$
A\left(\Omega ; \Omega_{0}\right)=\frac{\sqrt{5}}{4 \pi} P_{2}(\cos \gamma)=\frac{5}{16 \pi}(3 \cos \gamma+1)
$$

The shape of this averaging function tells us that we can know only an average of the slownesses equally weighted for $\Omega_{0}$ and for its antipode. The same is true for higher-order $(l=2,4, \ldots)$ spherical harmonics.

\section{Inter pretations of the Great Circle Phase Velocities}

Regional variations of Love and Rayleigh wave phase velocities will be estimated from their great circle averages measured in the previous section. For Rayleigh waves, many studies have been made, and recently Souriau and Souriau [1983] have interpreted the great circle phase velocities published during the last decade by using recent tectonic regionalization models. Their inversion results, however, show small variance reductions (less than about $30 \%$ for all the regionalization models used) in the period range from 150 to $350 \mathrm{~s}$. The small variance reductions must be caused by the inhomogeneity of their data set, which includes measurements of seven different authors who adopted a variety of methods to measure the phase velocities. All of the seven authors analyzed the seismograms obtained by digitizing photographic WWSSN records. No measurements or interpretations of long-period Love waves have appeared since the paper by Kanamori [1970]. Lévêque [1978] and R. G. North (unpublished manuscript, 1978) measured Love wave phase velocities and inverted them to obtain regionalized phase velocities. However, only one has been published, and it (the former) is not widely known in English-speaking countries, since it is written in French. Kanamori [1970] analyzed the Love waves recorded at WWSSN stations from two great earthquakes (1963, Kurile Islands; 1964, Alaska) and determined the Love wave regionalized phase velocities for average ocean, tectonically active region, and shield by incorporating the phase velocity data obtained in the 1960's. This three-region model may be inappropriate for the interpretation in the light of plate tectonics.

\section{Determination of Even Harmonics}

A least squares inversion of (12) is made to determine the even harmonics of the earth's lateral heterogeneity from Love and Rayleigh wave phase velocities in the period range from 100 to $330 \mathrm{~s}$. The inversions were made by truncating the spherical harmonics at $L=2,4,6$, and 8 . The results are presented in Figures 10 to 15 and in Tables 5 and 6 .

There are some differences in the variance reduction at-
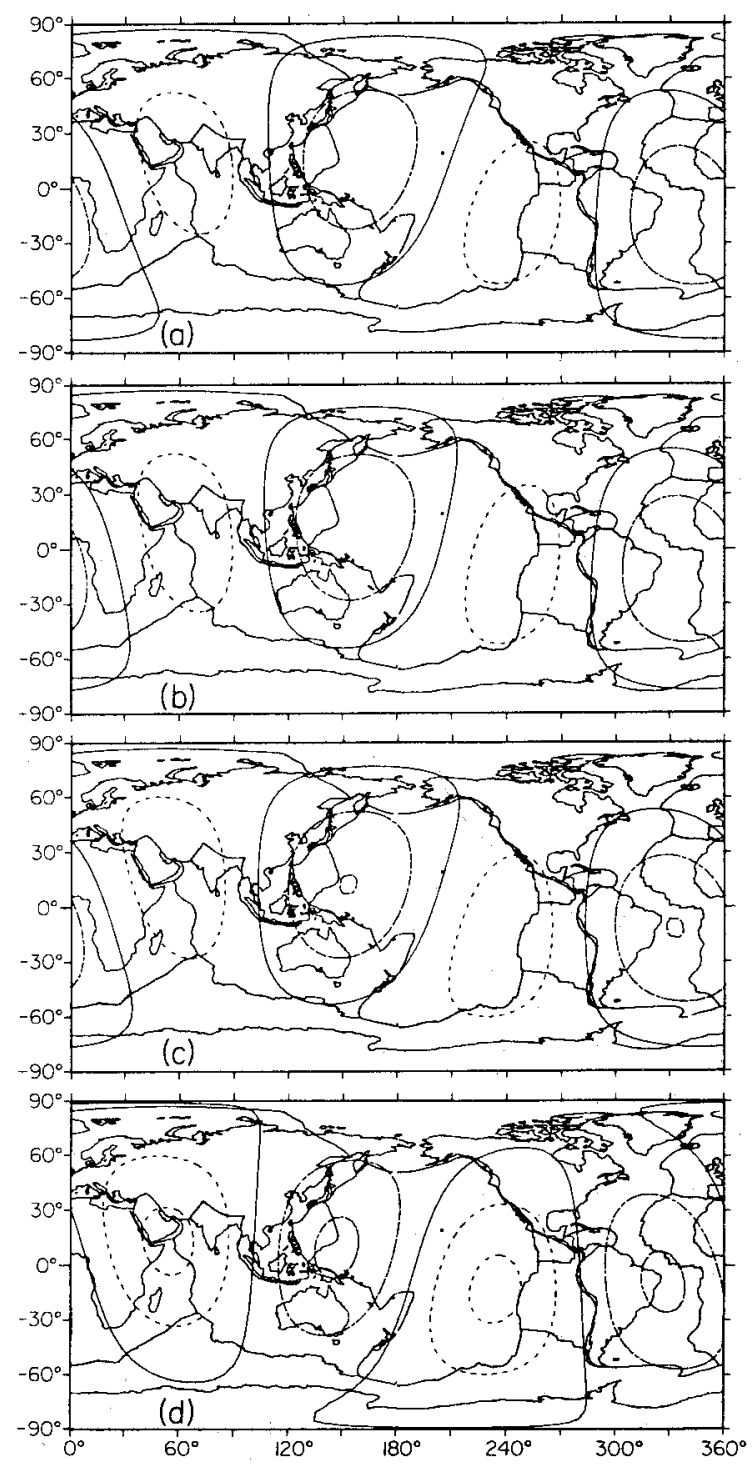

Fig. 14. Distribution of Rayleigh wave phase velocities synthesized from the results of the $L=2$ inversion. Conventions same as in Figure 12: (a) $148 \mathrm{~s},(b) 200 \mathrm{~s},(c) 250 \mathrm{~s},(d) 307 \mathrm{~s}$. 
tained by the inversions between Love (Figure 10) and Rayleigh (Figure 11) waves. For Love waves we have an increase in the variance reduction of about $10 \%$ to $15 \%$ in the whole period range when we change $L=2$ to 6 . Rayleigh waves show smaller increase of the variance reduction than Love waves, especially at periods longer than about $200 \mathrm{~s}$. In both cases the increase of $L=6$ to 8 does not improve the inversion. The variances are normalized by the number of degrees of freedom. The differences between Love and Rayleigh waves can be explained in terms of the penetration depth of these waves. For Rayleigh waves, at periods around $250 \mathrm{~s}$, the $l=2$ terms alone explain about $90 \%$ of the power of the variability. This variance reduction is equivalent to a reduction in standard deviation of about $70 \%$. This high variance reduction for Rayleigh wave phase velocities is consistent with Masters et al.'s [1982] results for spheroidal-mode periods. We should note here that this efficiency of the $l=2$ terms may partly be due to the structure of (12). As pointed out by Souriau and Souriau [1983] and Kawakatsu [1983], $P_{2}(0)(=-0.5)$ dominates the higher $P_{t}(0)\left(P_{4}(0)=0.375 ; P_{6}(0)=-0.312, \ldots\right)$. Therefore the $l=2$ terms contribute much more efficiently to the variance reduction. In other words the great circle integral acts as a low pass filter, which makes it difficult to detect shorter-wavelength lateral heterogeneity.

In determining $s_{l m}$ of (12), if the sampling of $\left(\Theta_{i}, \Phi_{i}\right)$ was sparse, we might have the problem of aliasing. However, we do not think this is a serious problem in the present case because our observations of azimuthal variation of phase velocities, such as Figures 6 to 9, show generally long wavelength variations. Furthermore, the great circle observation (or (12)) itself is a low pass operation and thus suppresses the aliasing.

Coefficients $\left(A_{l m}\right.$ and $\left.B_{l m}\right)$ of spherical harmonics and their standard deviations are listed in Tables 5 and 6 for $L=2$ (see convention (8)). The coefficients are determined in the inversion by correcting for the geometrical flattening $\left(f_{g}=\right.$ 1/297.001). The correction for the effect of the dynamical ellipticity [Dahlen, 1975, 1976; Dziewonski and Sailor, 1976] can be made easily. Dziewonski and Sailor's Table 2 and $f_{k}=$ 1/299.627 [Nakiboglu, 1982] are used here. The correction is

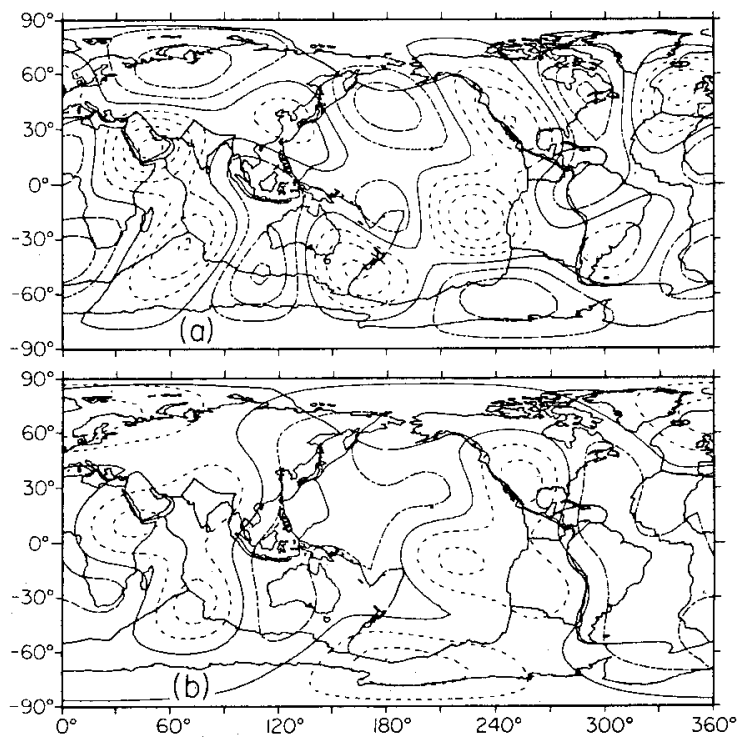

Fig. 15. Distribution of Rayleigh wave phase velocities synthesized from the results of the $L=6$ inversion. Conventions same as in Figure 12: (a) $148 \mathrm{~s},(b) 250 \mathrm{~s}$.
TABLE 5. $A_{l m}$ and $B_{l m}(l=0$ and 2$)$ for Love Wave Phase Slowness

\begin{tabular}{|c|c|c|c|c|c|c|}
\hline $\begin{array}{l}\text { Period, } \\
\text { s }\end{array}$ & $\begin{array}{c}A_{00} \\
\sigma\left(A_{00}\right)\end{array}$ & $\begin{array}{c}A_{20} \\
\sigma\left(A_{20}\right)\end{array}$ & $\begin{array}{c}A_{21} \\
\sigma\left(A_{21}\right)\end{array}$ & $\begin{array}{c}B_{21} \\
\sigma\left(B_{21}\right)\end{array}$ & $\begin{array}{c}A_{22} \\
\sigma\left(A_{22}\right)\end{array}$ & $\begin{array}{c}B_{22} \\
\sigma\left(B_{22}\right.\end{array}$ \\
\hline \multirow[t]{2}{*}{333.33} & 8765 & -1.6777 & -0.2057 & 4.0212 & -12.0670 & \\
\hline & & & & & & \\
\hline \multirow[t]{2}{*}{307.69} & & & & & & \\
\hline & & & & & & \\
\hline \multirow[t]{2}{*}{285.71} & & & & & & \\
\hline & & & & & & \\
\hline \multirow[t]{2}{*}{266.67} & & & & & & \\
\hline & & & & & & \\
\hline \multirow[t]{2}{*}{250.00} & & & & & & \\
\hline & & & & & & \\
\hline \multirow[t]{2}{*}{235.29} & & & & & & \\
\hline & & & & & & \\
\hline \multirow[t]{2}{*}{222.22} & & & & & & \\
\hline & & & & & & \\
\hline \multirow[t]{2}{*}{210.53} & & & & & & \\
\hline & & & & & & \\
\hline \multirow[t]{2}{*}{200.00} & & & & & & \\
\hline & & & & & & \\
\hline \multirow[t]{2}{*}{190.48} & & & & & & \\
\hline & & & & & & \\
\hline \multirow[t]{2}{*}{181.82} & & & & & & \\
\hline & & & & & & \\
\hline \multirow[t]{2}{*}{173.91} & & & & & & \\
\hline & & & & & & \\
\hline \multirow[t]{2}{*}{166.67} & & & & & & \\
\hline & & & & & & \\
\hline \multirow[t]{2}{*}{160.00} & & & & & & \\
\hline & & & & & & \\
\hline \multirow[t]{2}{*}{153.85} & & & & & & \\
\hline & & & & & & \\
\hline \multirow[t]{2}{*}{148.15} & & & & & & \\
\hline & & & & & & \\
\hline 142.86 & & & & & & \\
\hline & & & & & & \\
\hline & & & & & & \\
\hline & & & & & & \\
\hline 133.3 & & & & & 0 & \\
\hline & & & & & & \\
\hline & & & & & & \\
\hline & & & & & & \\
\hline 125.00 & & & & & 50 & \\
\hline & & & & & & \\
\hline & & & & & 0 & \\
\hline & & & & & & \\
\hline & & -2.3 & & & 0 & \\
\hline & & & & & & \\
\hline & & -2.3 & & & & \\
\hline & & & & & & \\
\hline & & -2 & & & 10 & \\
\hline & & & & & & \\
\hline 108.11 & & -2.06 & 5 & & -10.7 & \\
\hline & & & & & & 2.076 \\
\hline & & -176 & & & & \\
\hline & & & & & & \\
\hline & & & & & -11. & \\
\hline & & & & & & \\
\hline 100.00 & & -1.0827 & -0.5462 & 7.1066 & -11.2650 & \\
\hline & 0.90297 & 2.1186 & 1.6297 & 1.9312 & 1.9159 & 2.198 \\
\hline
\end{tabular}

Results of $L=2$ inversions with geometrical flattening. $A_{\mathrm{oo}}$ is in $\mathrm{s} / \mathrm{km} ; \sigma\left(A_{00}\right)$ is in $10^{-4} \mathrm{~s} / \mathrm{km} ; A_{2 m}, \sigma\left(A_{2 m}\right), B_{2 m}, \sigma\left(B_{2 m}\right)$ are in $10^{-4}$ $\mathrm{s} / \mathrm{km}$.

made in the following way. The phase velocity correction for the difference of the dynamical ellipticity from the geometrical ellipticity is

$$
\delta C=\frac{2}{\sqrt{5}} C_{00}\left[\chi_{2}(T)-\frac{1}{6} f_{g}\right] P_{2}\left(\cos \Theta_{i}\right)
$$

where $\chi_{2}(T)$ is given in Table 2 of Dziewonski and Sailor. This 
TABLE 6. $A_{l m}$ and $B_{l m}(l=0$ and 2) for Rayleigh Wave Phase Slowness

\begin{tabular}{|c|c|c|c|c|c|c|}
\hline $\begin{array}{l}\text { Period, } \\
\text { s }\end{array}$ & $\begin{array}{c}A_{00} \\
\sigma\left(A_{00}\right)\end{array}$ & $\begin{array}{c}A_{20} \\
\sigma\left(A_{20}\right)\end{array}$ & $\begin{array}{c}A_{21} \\
\sigma\left(A_{21}\right)\end{array}$ & $\begin{array}{c}B_{21} \\
\sigma\left(B_{21}\right)\end{array}$ & $\begin{array}{c}A_{22} \\
\sigma\left(A_{22}\right)\end{array}$ & $\begin{array}{c}B_{22} \\
\sigma\left(B_{22}\right)\end{array}$ \\
\hline \multirow[t]{2}{*}{333.33} & 0.18091 & 1.2870 & 2.9234 & -0.4577 & -4.6563 & 5.7139 \\
\hline & 0.47478 & 1.0272 & 0.8236 & 0.6890 & 1.0978 & 1.0194 \\
\hline \multirow{2}{*}{307.69} & 0.18705 & -0.0852 & 2.1572 & 0.8821 & -2.6696 & 7.1855 \\
\hline & 0.29406 & 0.6723 & 0.5793 & 0.4482 & 0.6880 & 0.5890 \\
\hline \multirow[t]{2}{*}{285.71} & 0.19292 & 1.6020 & 3.0650 & 0.2279 & -3.0531 & 5.5397 \\
\hline & 0.20606 & 0.4818 & 0.3920 & 0.3224 & 0.4865 & 0.4265 \\
\hline \multirow[t]{2}{*}{266.67} & 0.19839 & 1.6881 & 2.9371 & 0.0980 & -3.5549 & 5.8984 \\
\hline & 0.19496 & 0.4521 & 0.3681 & 0.3081 & 0.4566 & 0.4085 \\
\hline \multirow{2}{*}{250.00} & 0.20338 & 1.3596 & 2.6018 & 0.2924 & -4.0362 & 6.1464 \\
\hline & 0.17812 & 0.4095 & 0.3371 & 0.2839 & 0.4191 & 0.3733 \\
\hline \multirow[t]{2}{*}{235.29} & 0.20789 & 1.2987 & 2.3878 & 0.1240 & -4.3560 & 6.4182 \\
\hline & 0.18212 & 0.4095 & 0.3480 & 0.2912 & 0.4240 & 0.3821 \\
\hline \multirow[t]{2}{*}{222.22} & 0.21191 & 1.4089 & 2.2431 & -0.0413 & -4.5665 & 6.4753 \\
\hline & 0.18986 & 0.4305 & 0.3611 & 0.3053 & 0.4427 & 0.3984 \\
\hline \multirow{2}{*}{210.53} & 0.21547 & 1.3003 & 2.3003 & -0.0556 & -5.1427 & 6.5129 \\
\hline & 0.19589 & 0.4449 & 0.3718 & 0.3163 & 0.4569 & 0.4110 \\
\hline \multirow[t]{2}{*}{200.00} & 0.21861 & 1.3411 & 2.4896 & -0.1078 & -5.4755 & 6.4563 \\
\hline & 0.21100 & 0.4793 & 0.4005 & 0.3407 & 0.4922 & 0.4427 \\
\hline \multirow[t]{2}{*}{190.48} & 0.22140 & 1.2176 & 2.4897 & 0.1343 & -5.6056 & 6.4928 \\
\hline & 0.22927 & 0.5208 & 0.4352 & 0.3702 & 0.5348 & 0.4810 \\
\hline \multirow{2}{*}{181.82} & 0.22391 & 0.9546 & 2.5222 & 0.3089 & -5.8962 & 6.6756 \\
\hline & 0.24183 & 0.5498 & 0.4594 & 0.3898 & 0.5636 & 0.5075 \\
\hline \multirow{2}{*}{173.91} & 0.22614 & 1.0780 & 2.6905 & 0.1491 & -6.2382 & 6.5829 \\
\hline & 0.25082 & 0.5699 & 0.4702 & 0.4021 & 0.5826 & 0.5268 \\
\hline \multirow[t]{2}{*}{166.67} & 0.22815 & 1.3355 & 3.0112 & 0.2555 & -6.7683 & 6.4620 \\
\hline & 0.28715 & 0.6467 & 0.5364 & 0.4635 & 0.6644 & 0.6033 \\
\hline \multirow{2}{*}{160.00} & 0.22995 & 1.1420 & 2.9141 & 0.4542 & -6.6150 & 6.1813 \\
\hline & 0.31310 & 0.7163 & 0.5799 & 0.5030 & 0.7203 & 0.6620 \\
\hline \multirow[t]{2}{*}{153.85} & 0.23157 & 0.8553 & 2.9607 & 0.4562 & -6.1913 & 6.3386 \\
\hline & 0.34555 & 0.7835 & 0.6400 & 0.5554 & 0.7907 & 0.7238 \\
\hline \multirow[t]{2}{*}{148.15} & 0.23301 & 0.8724 & 3.4005 & 0.4248 & -5.9676 & 6.2674 \\
\hline & 0.37510 & 0.8316 & 0.6947 & 0.5871 & 0.8606 & 0.7683 \\
\hline 142.86 & 0.23430 & 0.5261 & 3.7371 & 0.4908 & -5.7783 & 6.2513 \\
\hline & 0.39799 & 0.8788 & 0.7337 & 0.6295 & 0.9161 & 0.8295 \\
\hline 137.93 & 0.23556 & 1.2128 & 3.6173 & 0.6371 & -6.3531 & 6.1187 \\
\hline & 0.42460 & 0.9479 & 0.7834 & 0.6832 & 0.9744 & 0.8839 \\
\hline 133.33 & 0.23666 & 1.3177 & 4.3259 & 0.4329 & -6.9915 & 5.1912 \\
\hline & 0.46460 & 1.0070 & 0.8890 & 0.7465 & 1.0765 & 0.9415 \\
\hline 129.03 & 0.23767 & 1.0134 & 3.5215 & 1.2017 & -7.1706 & 3.8130 \\
\hline & 0.52022 & 1.1252 & 0.9795 & 0.8246 & 1.2148 & 1.0572 \\
\hline 125.00 & 0.23860 & 0.4108 & 3.8244 & 1.2006 & -7.5238 & 3.9696 \\
\hline & 0.53271 & 1.1592 & 1.0172 & 0.8689 & 1.2376 & 1.1177 \\
\hline 121.21 & 0.23944 & 0.4837 & 4.3806 & 1.1783 & -7.2159 & 4.5676 \\
\hline & 0.57519 & 1.2363 & 1.0938 & 0.9344 & 1.3284 & 1.1948 \\
\hline 117.65 & 0.24026 & 0.8509 & 4.6914 & 1.9598 & -7.2759 & 4.8732 \\
\hline & 0.60385 & 1.2852 & 1.1354 & 0.9782 & 1.4391 & 1.2424 \\
\hline 114.29 & 0.24102 & 0.2013 & 5.7160 & 2.8355 & -6.9095 & 6.3077 \\
\hline & 0.69271 & 1.4629 & 1.2743 & 1.0995 & 1.6436 & 1.4224 \\
\hline 111.11 & 0.24169 & 1.2739 & 5.9288 & 4.0807 & -7.6297 & 7.7645 \\
\hline & 0.74486 & 1.6124 & 1.3704 & 1.2065 & 1.7442 & 1.5863 \\
\hline 108.11 & 0.24227 & 2.2619 & 5.5140 & 4.2944 & -7.5233 & 6.5692 \\
\hline & 0.84281 & 1.7508 & 1.5811 & 1.3950 & 1.9435 & 1.7424 \\
\hline 105.26 & 0.24290 & 1.6142 & 4.6850 & 5.1576 & -7.5299 & 7.0539 \\
\hline & 0.97310 & 1.9827 & 1.7861 & 1.5746 & 2.2786 & 1.9532 \\
\hline 102.56 & 0.24351 & 1.1063 & 4.1644 & 5.4493 & -7.4378 & 8.0010 \\
\hline & 1.04210 & 2.1416 & 1.9662 & 1.7391 & 2.4116 & 2.1290 \\
\hline 100.00 & 0.24416 & 0.2012 & 4.0729 & 5.9236 & -6.7449 & 8.6632 \\
\hline & 1.14860 & 2.3605 & 2.1671 & 1.9168 & 2.6580 & 2.3466 \\
\hline
\end{tabular}

Results of $L=2$ inversions with the geometrical flattening. $A_{00}$ is in $\mathrm{s} / \mathrm{km} ; \sigma\left(A_{00}\right)$ is in $10^{-4} \mathrm{~s} / \mathrm{km} ; A_{2 m}, \sigma\left(A_{2 m}\right), B_{2 m}, \sigma\left(B_{2 m}\right)$ are in $10^{-4}$ $\mathrm{s} / \mathrm{km}$.

means that we solved

$$
\begin{array}{r}
\frac{1}{C\left(\Theta_{i}, \Phi_{i}\right)-\delta C}=\sum_{l=\text { even }}^{L} P_{l}(0) \sum_{m=-l}^{m=l} s_{l m}{ }^{\prime} Y_{l m}\left(\Theta_{i}, \Phi_{i}\right) \\
i=1, \ldots, N
\end{array}
$$

instead of (12), where $C\left(\Theta_{i}, \Phi_{i}\right)$ is the phase velocity corrected for the dynamical ellipticity. Therefore, to obtain $s_{20}$ of (12), we have to make the following correction:

$$
s_{20}=s_{20}{ }^{\prime}+\frac{4}{\sqrt{5}} s_{00}^{\prime}\left[\chi_{2}(T)-\frac{1}{6} f g\right]
$$

where $P_{2}(0)=-0.5$ and $s_{l m}{ }^{\prime}=s_{l m}$, except for $l m=20$.

Velocity distributions are synthesized by using the even harmonics determined in the inversions (Figures 12 to 15). For Love waves, and for shorter-period Rayleigh waves, there are some changes in patterns of the velocity distribution between $L=2$ and 6. On the other hand, longer-period Rayleigh waves (Figure $14 c, d$ and Figure $15 b$ ) have slight changes in the velocity pattern when we increase $L=2$ to $L=6$. As Figure 14 shows, our results of $L=2$ inversion of Rayleigh wave phase velocities show a pattern similar to that of spheroidalmode eigenfrequencies obtained by Masters et al. [1982]. High velocity appears in the western Pacific and the central Atlantic, low velocity in the eastern Pacific and the Middle East. The Love wave results (Figure 12) show a generally similar pattern of the $L=2$ heterogeneity, although the amplitude of the variations is larger. The $l=2$ part of the earth's heterogeneity is, of course, symmetric, and the above results do not necessarily imply that all of the above regions are anomalous. A slow region centered on the East Pacific Rise would also appear at the antipode, in the Middle Eastnorthern Indian Ocean, on an $l=2$, or on any other evenharmonic map.

\section{Regionalized Phase Velocities}

The same data set (great circle phase velocities) is also inverted to yield regionalized phase velocities. Recently, Souriau and Souriau [1983] made regionalized inversions of great circle Rayleigh wave phase velocities by using the regionalization models of $0 \mathrm{kal}$ [1977], Lévêque [1980], and Jordan [1981]. They showed that Okal's regionalization provides the best fit to great circle phase velocities in the period range between 150 and $350 \mathrm{~s}$. Okal's model has a region $(T)$ that is dominated by regions of convergence and, in this respect, differs from Jordan's regionalization. Here we present results derived by using Okal's model, which is shown in

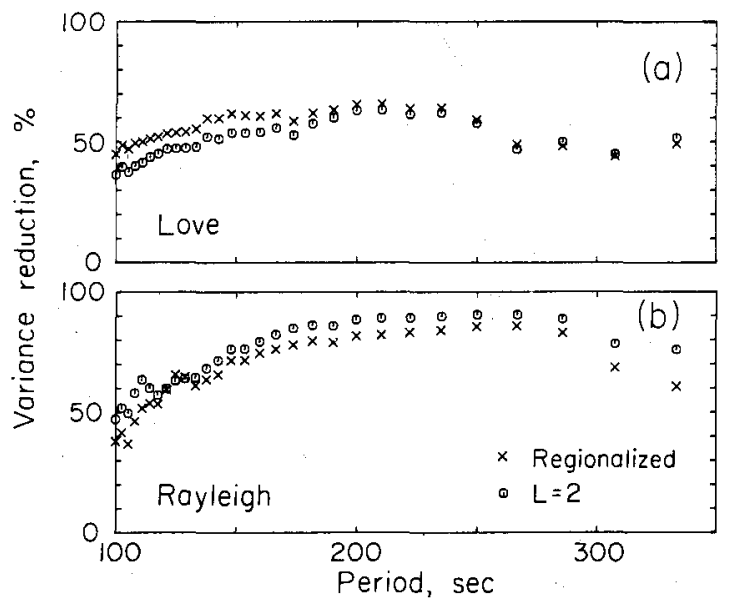

Fig. 16. Variance reduction of the regionalized inversion as compared with the $L=2$ inversion. Open circle indicates the $L=2$ inversion. Cross represents the regionalized inversion using Okal's model. See Figure 10 for definition of variance reduction: (a) Love waves, (b) Rayleigh waves. 


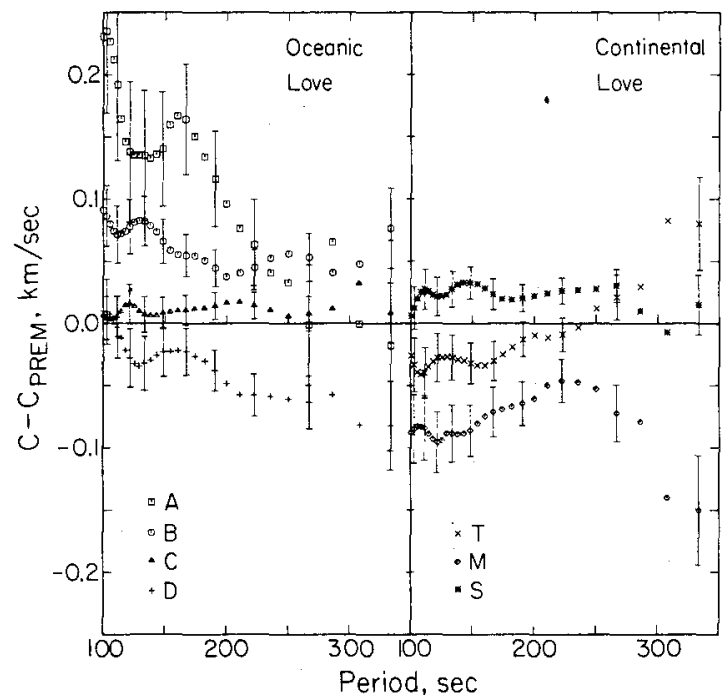

Fig. 17. Regionalized Love wave phase velocities. Deviations from PREM are shown. Symbol conventions are shown in the figure and in Figure 5. For example, $S$ indicates shield region. Error bars mean the standard deviation of the least squares estimates.

Figure 5. The results of the regionalized inversions are presented in Figures 16, 17, and 18 and in Tables 7 and 8.

Love wave phase velocities (Figure 17) show larger regional variations than those of Rayleigh waves (Figure 18). The variance reduction (Figure 16) is smaller for Love waves than for Rayleigh waves. These two results are consistent. For the period range of this study, Love waves are more affected by the structure at shallower depths than are Rayleigh waves. This leads to larger regional variations for Love waves and may introduce scatter due to lateral refraction, reflection, and conversion. Azimuthal variation of Love wave phase velocity, calculated from the regionalized values obtained here and the results of the $L=2$ and $L=6$ inversions, is compared with the observed velocities. Figures 6 and 7 show examples for the Santa Cruz Islands (event 12) and the Eureka earthquake (event 24). The phase velocity calculated from Kanamori's [1970] regionalized phase velocities is also shown for com-

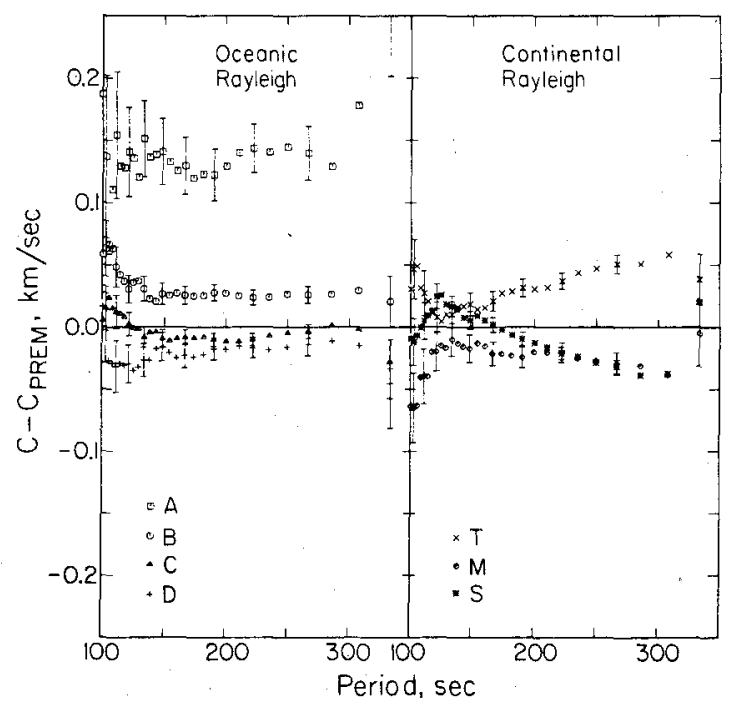

Fig. 18. Regionalized Rayleigh wave phase velocities. Conventions same as in Figure 17.
TABLE 7. Regionalized Love Wave Phase Velocities Obtained by Using Okal's Regionalization

\begin{tabular}{|c|c|c|c|c|c|c|c|}
\hline Period, s & A & B & $\mathrm{C}$ & D & $\mathrm{T}$ & $\mathbf{M}$ & $\mathrm{S}$ \\
\hline \multirow[t]{2}{*}{333.33} & 5.3180 & 5.4123 & 5.3442 & 5.2536 & 5.4159 & 5.1854 & 5.3507 \\
\hline & 0.0846 & 0.0322 & 0.0242 & 0.0359 & 0.0373 & 0.0441 & 0.0240 \\
\hline \multirow[t]{2}{*}{307.69} & 5.2531 & 5.3015 & 5.2860 & 5.1720 & 5.3357 & 5.1130 & 5.2462 \\
\hline & 0.0714 & 0.0263 & 0.0201 & 0.0309 & 0.0276 & 0.0323 & 0.0174 \\
\hline \multirow{2}{*}{285.71} & 5.2485 & 5.2241 & 5.1953 & 5.1256 & 5.2125 & 5.1040 & 5.1933 \\
\hline & 0.0565 & 0.0216 & 0.0157 & 0.0242 & 0.0207 & 0.0253 & 0.0144 \\
\hline \multirow[t]{2}{*}{266.67} & 5.1217 & 5.1761 & 5.1309 & 5.0595 & 5.1440 & 5.0508 & 5.1536 \\
\hline & 0.0484 & 0.0194 & 0.0139 & 0.0213 & 0.0181 & 0.0229 & 0.0133 \\
\hline \multirow[t]{2}{*}{250.00} & 5.1034 & 5.1268 & 5.0764 & 5.0097 & 5.0824 & & 5.0984 \\
\hline & 0.0413 & 0.0162 & 0.0118 & 0.0184 & 0.0154 & 0.0192 & 0.0114 \\
\hline \multirow[t]{2}{*}{235.29} & 5.0663 & 5.0781 & 5.0363 & 4.9668 & 5.0220 & 4.9778 & 5.0521 \\
\hline & 0.0372 & 0.0151 & 0.0109 & 0.0172 & 0.0140 & 0.0178 & 0.0107 \\
\hline \multirow[t]{2}{*}{222.22} & 5.0487 & 5.0304 & 4.9998 & 4.9278 & 4.9763 & 4.9392 & 5.0117 \\
\hline & 0.0364 & 0.0145 & 0.0107 & 0.0169 & 0.0136 & 0.0175 & 0.0105 \\
\hline \multirow{2}{*}{210.53} & 5.0264 & 4.9908 & 4.9675 & 4.8926 & 4.9388 & 4.90 & 4.9745 \\
\hline & 0.03 & 0.01 & 0.0 & 0.0 & 0.0 & & 0.0104 \\
\hline \multirow[t]{2}{*}{200.00} & 5.0151 & 4.9566 & 4.9356 & 4.8706 & 4.9095 & 4.8585 & 4.9413 \\
\hline & 0.0364 & 0.01 & 0.0103 & 0.01 & 0.0134 & 0.0170 & 0.0105 \\
\hline \multirow[t]{2}{*}{190.48} & 5.0071 & 4.93 & 4.9 & 4.8 & 4.8777 & 4.8262 & 4.9112 \\
\hline & 0.0383 & 0.0149 & 0.0 & 0.01 & 0.0 & & 0.0109 \\
\hline \multirow[t]{2}{*}{181.82} & 4.9999 & 4.9168 & 4.87 & 4.8 & 4.8 & 4.7 & 4.8853 \\
\hline & 0.040 & & 0.01 & 0.01 & 0.0 & & 114 \\
\hline \multirow[t]{2}{*}{173.91} & 4.993 & 4.89 & 4.8553 & $4.81 \mathrm{t}$ & 4.81 & 4.7742 & 4.8631 \\
\hline & 0.0427 & 0.0164 & 0.0118 & 0.0182 & 0.0152 & 0.0194 & 0.0120 \\
\hline \multirow[t]{2}{*}{166.67} & 4.9871 & 4.87 & 4.8338 & 4.8003 & 4.7925 & 4.7516 & 4.8465 \\
\hline & 0.0446 & $0.01^{\prime}$ & 0.01 & 0.0 & 0.01 & 0.0 & 0.0124 \\
\hline \multirow[t]{2}{*}{160.00} & 4.9707 & 4.8593 & 4.8142 & 4.7819 & 4.7701 & 4.7294 & 4.8325 \\
\hline & 0.0458 & 0.01 & 0.0126 & 0.0194 & 0.0161 & 0.0206 & 0.0128 \\
\hline \multirow[t]{2}{*}{153.85} & 4.9467 & 4.84 & 4.7966 & & 4.75 & & 4.8190 \\
\hline & 0.0461 & 0.01 & 0.0127 & 0.01 & 0.0163 & 0.0207 & 0.0129 \\
\hline \multirow[t]{2}{*}{148.15} & 4.9114 & 4.8372 & 4.7796 & 4.7481 & 4.7391 & 4.6851 & 4.8042 \\
\hline & 0.0459 & $0.01^{\prime}$ & 0.0127 & 0.0196 & 0.0163 & 0.0207 & 0.0130 \\
\hline 142.86 & 4.8927 & 4.8305 & 4.7633 & 4.7310 & 4.7268 & 4.6684 & 4.7898 \\
\hline & 0.0485 & 0.01 & 0.0132 & 0.0203 & 0.0169 & 0.0213 & 0.0134 \\
\hline 137.93 & 4.8762 & 4.82 & & 4.71 & 4.7145 & & 4.7750 \\
\hline & & & & 0.0 & 0.0 & 20 & 0.0139 \\
\hline 133.33 & 4.8660 & 4.8134 & 4.7383 & 4.6987 & 4.7036 & 4.6427 & 4.7589 \\
\hline & 0.0524 & 0.0199 & 0.0144 & 0.0217 & 0.0182 & 0.0229 & 0.0144 \\
\hline 129.03 & 4.8548 & 4.8023 & 4.7293 & 4.6848 & 4.6927 & 4.6312 & 4.7428 \\
\hline & 0.0547 & 0.0209 & 0.0150 & 0.0226 & 0.0189 & 0.0238 & 0.0151 \\
\hline 125.00 & 4.8440 & 4.7902 & 4.7225 & 4.6761 & 4.6809 & 4.6144 & 4.7305 \\
\hline & & & & 0.0231 & & 0.0243 & 0.0153 \\
\hline 121.21 & & & & 4.6706 & & 4.6026 & 4.7200 \\
\hline & & 0.0219 & 0.0156 & 0.0235 & 0.0195 & 0.0246 & 0.0155 \\
\hline 117.65 & 4.8352 & 4.7634 & 4.7038 & 4.6674 & 4.6583 & 4.5961 & 4.7123 \\
\hline & 0.0576 & 0.0221 & 0.0158 & 0.0233 & 0.0200 & 0.0252 & 0.0157 \\
\hline 114.29 & 4.8443 & 4.7524 & 4.6896 & 4.6681 & 4.6447 & 4.5910 & 4.7059 \\
\hline & 0.0590 & 0.0226 & 0.0161 & 0.0244 & 0.0201 & 0.0255 & 0.0159 \\
\hline 111.11 & 4.8634 & 4.7430 & 4.6774 & 4.6680 & 4.6312 & 4.5869 & 4.6988 \\
\hline & 0.0612 & 0.0229 & 0.0164 & 0.0248 & 0.0204 & 0.0260 & 0.0162 \\
\hline 108.11 & 4.8757 & 4.7378 & 4.6676 & 4.6666 & 4.6220 & 4.5801 & 4.6886 \\
\hline & & 0.0234 & 0.0166 & 0.0253 & 0.0208 & 0.0264 & 0.0165 \\
\hline 105.26 & 4.8825 & 4.7361 & 4.6595 & 4.6630 & 4.6163 & 4.5731 & 4.6757 \\
\hline & 0.0643 & 0.0239 & 0.0169 & 0.0258 & 0.0212 & 0.0269 & 0.0168 \\
\hline 102.56 & 4.8839 & 4.7354 & 4.6533 & 4.6581 & 4.6150 & 4.5638 & 4.6612 \\
\hline & 0.0659 & 0.0244 & 0.0173 & 0.0263 & 0.0216 & 0.0274 & 0.0172 \\
\hline 100.00 & 4.8724 & 4.7329 & 4.6483 & 4.6513 & 4.6158 & 4.5540 & 4.6482 \\
\hline & 0.0672 & 0.0249 & 0.0177 & 0.0269 & 0.0221 & 0.0280 & 0.0175 \\
\hline
\end{tabular}

All values in $\mathrm{km} / \mathrm{s}$. First row of each entry, $C$; second row, $\sigma C$; both in kilometers per second.

parison. He used Plate 5 of Umbgrove [1947]. Since we found that his regionalization model is very similar to that of Dziewonski and Steim [1982], except for the young oceanic region (H. Kanamori, personal communication, 1983), we combined the young and old oceans of Dziewonski and Steim and used this modified regionalization to calculate the azimuthal variations of Love waves from Kanamori's regionalized values. 
TABLE 8. Regionalized Rayleigh Wave Phase Velocities Obtained by Using Okal's Regionalization

\begin{tabular}{|c|c|c|c|c|c|c|c|}
\hline Period, s & A & B & $\mathrm{C}$ & $\mathrm{D}$ & $\mathrm{T}$ & M & S \\
\hline \multirow[t]{2}{*}{333.33} & 5.8104 & 5.5480 & 5.4996 & 5.4700 & 5.5655 & 5.5220 & 5.5478 \\
\hline & 0.0817 & 0.0205 & 0.0177 & 0.0240 & 0.0203 & 0.0263 & 0.0200 \\
\hline \multirow[t]{2}{*}{307.69} & 5.5254 & 5.3761 & 5.3451 & 5.3325 & 5.4050 & 5.3082 & 5.3095 \\
\hline & 0.0372 & 0.0111 & 0.0096 & 0.0149 & 0.0124 & 0.0154 & 0.0094 \\
\hline \multirow[t]{2}{*}{285.71} & 5.3135 & 5.2110 & 5.1856 & 5.1734 & 5.2353 & 5.1532 & 5.1459 \\
\hline & 0.0243 & 0.0076 & 0.0063 & 0.0101 & 0.0085 & 0.0102 & 0.0064 \\
\hline \multirow[t]{2}{*}{266.67} & 5.18 & 5.0678 & 5.0384 & 5.0279 & 5.0925 & 5.0126 & 5.0100 \\
\hline & 0.0216 & 0.0068 & 0.0057 & 0.0090 & 0.0076 & 0.0090 & 0.0056 \\
\hline \multirow[t]{2}{*}{250.00} & 5.0629 & 4.9449 & 4.9136 & 4.9023 & 4.9650 & 4.8909 & 4.8895 \\
\hline & 0.0192 & 0.0060 & 0.0050 & 0.0080 & 0.0067 & 0.0079 & 0.0050 \\
\hline \multirow{2}{*}{235.29} & 4.9528 & 4.8363 & 4.8053 & 4.7939 & 4.8559 & 4.7871 & 4.7886 \\
\hline & 0.0195 & 0.0060 & 0.0050 & 0.0081 & 0.0065 & 0.0078 & 0.0049 \\
\hline \multirow[t]{2}{*}{222.22} & 4.8650 & 4.7453 & 4.7116 & 4.7048 & 4.7585 & 4.7010 & 4.7005 \\
\hline & 0.0195 & 0.0060 & 0.0050 & 0.0082 & 0.0066 & 0.0079 & 0.0050 \\
\hline \multirow[t]{2}{*}{210.53} & 4.7838 & 4.6690 & 4.6322 & 4.6285 & 4.6754 & 4.6232 & 4.6277 \\
\hline & 0.0198 & 0.0062 & 0.0051 & 0.0084 & 0.0 & 0.0081 & 0.0051 \\
\hline \multirow[t]{2}{*}{200.00} & 4.7058 & 4.6039 & 4.5650 & 4.5586 & 4.6072 & 4.5567 & 4.5642 \\
\hline & 0.02 & 0.0063 & 0.0053 & 0.0086 & 0.0069 & 0.0083 & 0.0052 \\
\hline \multirow[t]{2}{*}{190.48} & 4.6409 & 4.5464 & 4.5084 & 4.5010 & 4.5499 & 4.4941 & 4.5092 \\
\hline & 0.0208 & 0.0065 & 0.0054 & 0.0088 & 0.0071 & 0.0085 & 0.0054 \\
\hline \multirow[t]{2}{*}{181.82} & 4.5907 & 4.4933 & 4.4598 & 4.4456 & 4.4962 & 4.4450 & 4.4614 \\
\hline & 0.0215 & 0.0067 & 0.0056 & 0.0091 & 0.0073 & 0.0088 & 0.0055 \\
\hline \multirow[t]{2}{*}{173.91} & 4.5432 & 4.4485 & 4.4147 & 4.3992 & 4.4501 & 4.4017 & 4.4212 \\
\hline & 0.0214 & 0.0068 & 0.0057 & 0.005 & 0.0 & 0.0 & 0.0056 \\
\hline \multirow[t]{2}{*}{166.67} & 4.5134 & 4.4095 & 4.3756 & 4.3609 & 4.4048 & 4.3626 & 4.3859 \\
\hline & 0.0229 & 0.0072 & 0.0061 & 0.0098 & 0.0079 & 0.0096 & 0.0060 \\
\hline \multirow[t]{2}{*}{160.00} & 4.4746 & 4.3765 & 4.3400 & 4.3241 & 4.3644 & 4.3339 & 4.3548 \\
\hline & 0.0235 & 0.0076 & 0.0063 & 0.0101 & 0.00 & 0.0 & 0.0061 \\
\hline \multirow[t]{2}{*}{153.85} & 4.4506 & 4.3435 & 4.3069 & 4.2972 & 4.3319 & 4.3049 & 4.3270 \\
\hline & 0.0252 & 0.0081 & 0.0067 & 0.0109 & 0.0087 & 0.0 & 0.0066 \\
\hline \multirow[t]{2}{*}{148.15} & 4.4308 & 4.3167 & 4.2808 & 4.2740 & 4.3083 & 4.2727 & 4.2958 \\
\hline & 0.0266 & 0.0087 & 0.0072 & 0.0114 & 0.0092 & 0.0112 & 0.0072 \\
\hline 142.86 & 4.4037 & 4.2858 & 4.2614 & 4.2476 & 4.2818 & 4.2495 & 4.2730 \\
\hline & 0.0280 & 0.0092 & 0.0076 & 0.0118 & 0.0097 & 0.0119 & 0.0076 \\
\hline 137.93 & 4.3786 & 4.2649 & 4.2377 & 4.2153 & 4.2580 & 4.2290 & 4.2562 \\
\hline & 0.0291 & 0.0095 & 0.0078 & 0.0121 & 0.0100 & 0.0126 & 0.0078 \\
\hline 133.33 & 4.3728 & 4.2525 & 4.2135 & 4.1948 & 4.2316 & 4.2114 & 4.2386 \\
\hline & 0.0306 & 0.0100 & 0.0082 & 0.0134 & 0.0105 & 0.0132 & 0.0084 \\
\hline 129.03 & 4.3230 & 4.2398 & 4.2013 & 4.1701 & 4.2125 & 4.1855 & 4.2209 \\
\hline & 0.0326 & 0.0102 & 0.0086 & 0.0138 & 0.0110 & 0.0141 & 0.0090 \\
\hline 125.00 & 4.32 & 4.2211 & 4.1842 & 4.1499 & 4.1895 & 4.1701 & 4.2108 \\
\hline & 0.0327 & 0.0102 & 0.0084 & 0.0136 & 0.0108 & 0.0141 & 0.0089 \\
\hline 121.21 & 4.3100 & 4.1999 & 4.1718 & 4.1394 & 4.1769 & 4.1497 & 4.1941 \\
\hline & 0.0358 & 0.0111 & 0.0094 & 0.0153 & 0.0123 & 0.0157 & 0.0101 \\
\hline 117.65 & 4.2830 & 4.1920 & 4.1634 & 4.1239 & 4.1665 & 4.1350 & 4.1680 \\
\hline & 0.0377 & 0.0120 & 0.0100 & 0.0159 & 0.0136 & 0.0170 & 0.0109 \\
\hline 114.29 & 4.2708 & 4.1839 & 4.1526 & 4.1121 & 4.1618 & 4.1019 & 4.1507 \\
\hline & 0.0434 & 0.0135 & 0.0117 & 0.0183 & 0.0161 & 0.0195 & 0.0132 \\
\hline 111.11 & 4.2833 & 4.1776 & 4.1412 & 4.0971 & 4.1562 & 4.0893 & 4.1340 \\
\hline & 0.0510 & 0.0162 & 0.0135 & 0.0208 & 0.0181 & 0.0221 & 0.0148 \\
\hline 108.11 & 4.2283 & 4.1811 & 4.1330 & 4.0885 & 4.1492 & 4.0772 & 4.1176 \\
\hline & 0.0530 & 0.0178 & 0.0145 & 0.0228 & 0.0198 & 0.0238 & 0.0158 \\
\hline 105.26 & 4.1684 & 4.1738 & 4.1309 & 4.0801 & 4.1562 & 4.0441 & 4.1004 \\
\hline & 0.0580 & 0.0215 & 0.0168 & 0.0261 & 0.0236 & 0.0276 & 0.0176 \\
\hline 102.56 & 4.2345 & 4.1608 & 4.1127 & 4.0967 & 4.1438 & 4.0322 & 4.0854 \\
\hline & 0.0652 & 0.0223 & 0.0179 & 0.0281 & 0.0240 & 0.0280 & 0.0189 \\
\hline 100.00 & 4.2751 & 4.1468 & 4.0937 & 4.1046 & 4.1187 & 4.0246 & 4.0789 \\
\hline & 0.0721 & 0.0240 & 0.0192 & 0.0306 & 0.0258 & 0.0302 & 0.0204 \\
\hline
\end{tabular}

All values in $\mathrm{km} / \mathrm{s}$. First row of each entry, $C$; second row, $\sigma C$; both in kilometers per second.

Rayleigh wave regionalized phase velocities obtained here are consistent with Souriau and Souriau's [1983] results for Okal's model. In Figure 18, region A (ocean older than 135 m.y.) shows an extremely high Raleigh wave phase velocity as compared with the other oceanic regions (B, C, and D). Souriau and Souriau also obtained very high phase velocities for region $A$. The high velocity might be partly caused by the instability due to the small area of region $A$. Region $T$
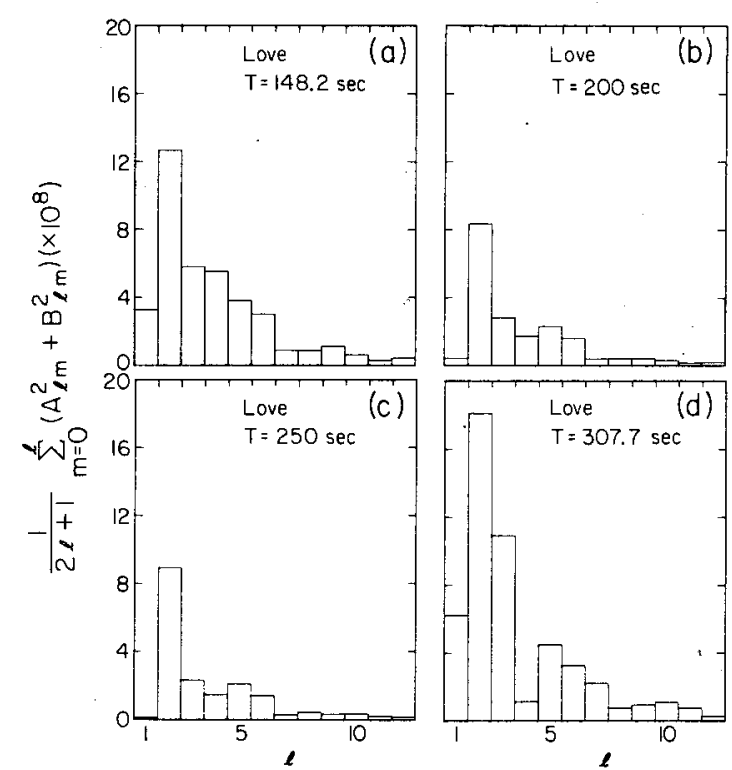

Fig. 19. Power spectra of the regionalized Love wave phase velocities: (a) $148 \mathrm{~s},(b) 200 \mathrm{~s},(c) 250 \mathrm{~s},(d) 307 \mathrm{~s}$.

(trenches, island arcs, back-arc basins) exhibit low velocities at short periods and very high velocities at long periods. This indicates a slow shallow mantle underlain by fast material. Region $\mathrm{T}$, on average, is faster than shield region $\mathrm{S}$ at long periods. Figures 8 and 9 compare the great circle phase velocities calculated from the regionalized phase velocities and the results of $L=2$ and 6 inversions with those observed for the Santa Cruz Islands and Eureka earthquakes. The calculated phase velocities for Dziewonski and Steim's [1982] and Souriau and Souriau's [1983] regionalized phase velocities are shown for comparison. Dziewonski and Steim's phase velocities do not predict the observed values for the Eureka earthquake (Figure 9) in the azimuth range from $10^{\circ}$ to $60^{\circ}$. This discrepancy between observed and calculated phase velocities for earthquakes in western North America has been noted and discussed by Nakanishi and Kanamori [1982] for an earthquake in the California-Mexico border region (event 8).

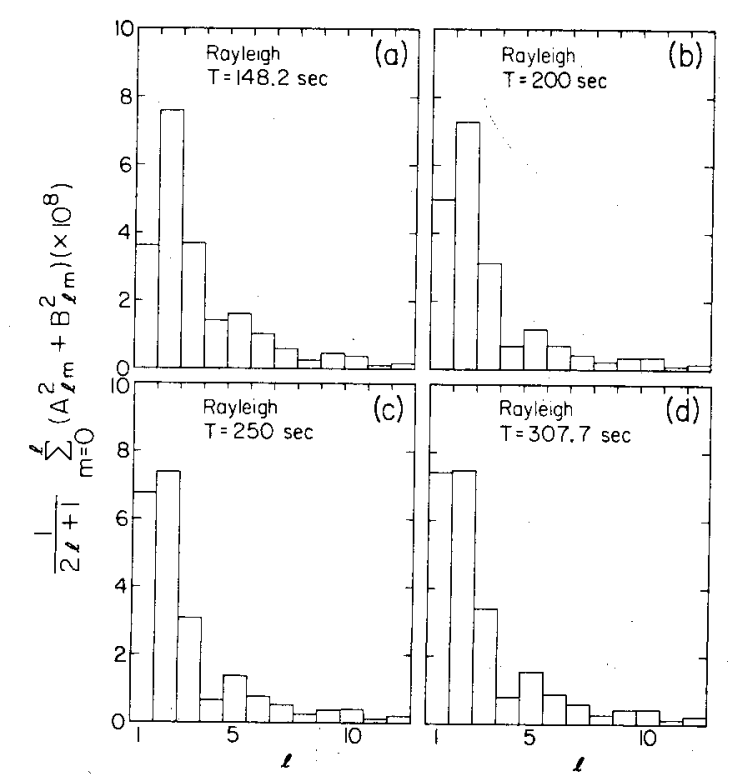

Fig. 20. Power spectra of the regionalized Rayleigh wave phase velocities: (a) $148 \mathrm{~s},(b) 200 \mathrm{~s},(c) 250 \mathrm{~s},(d) 307 \mathrm{~s}$. 
Spherical Harmonic Expansion of Regionalized Phase Velocities

We make a spatial spectral analysis of the regionalized phase velocities derived in the above section. We first expand the regionalization $n_{j}(\Omega)$ of (13) in spherical harmonics (15), and then, using (17), we obtain the spherical harmonic coefficients of the regionalized phase slownesses. In the numerical integration for calculating $r_{l m}{ }^{j}$ of (15) we used the trapezoidal cubature formula and a grid size of $1^{\circ} \times 1^{\circ}$. We calculated the coefficients up to degree and order 12 . This corresponds to the grid size $\left(15^{\circ} \times 15^{\circ}\right)$ of $\mathrm{Okal}$ 's [1977] regionalization. The power spectra of the regionalized phase velocities are shown in Figures 19 and 20. Note that there is a general tendency for the normalized power to die off from $l=2$ to $l=7$ and to remain very small for larger $l$. The $l=2$ term dominates for Love waves, and $l=1$ and $l=2$ are both large for Rayleigh waves. The $l=$ odd terms are not negligible. The velocity distributions synthesized by using the $l=2$ terms alone are presented in Figures 21 and 22. In the appendix we show velocity
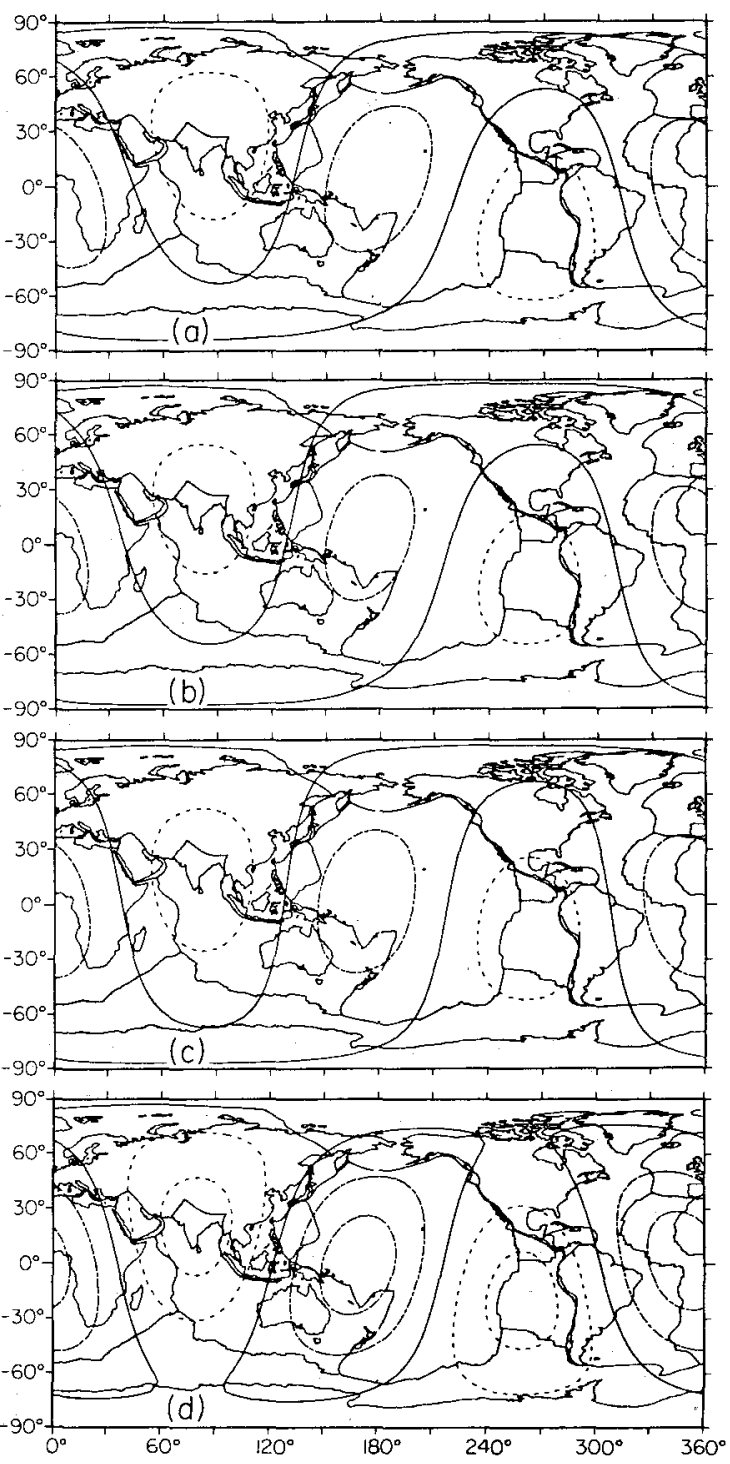

Fig. 21. Distribution of Love wave phase velocity synthesized by using the $l=2$ coefficients obtained by spherical harmonic expansion of the regionalized phase velocities. The contour interval is $0.02 \mathrm{~km} / \mathrm{s}$. Symbol conventions same as in Figure 12:(a) $148 \mathrm{~s},(b) 200 \mathrm{~s},(c) 250 \mathrm{~s}$, (d) $307 \mathrm{~s}$.
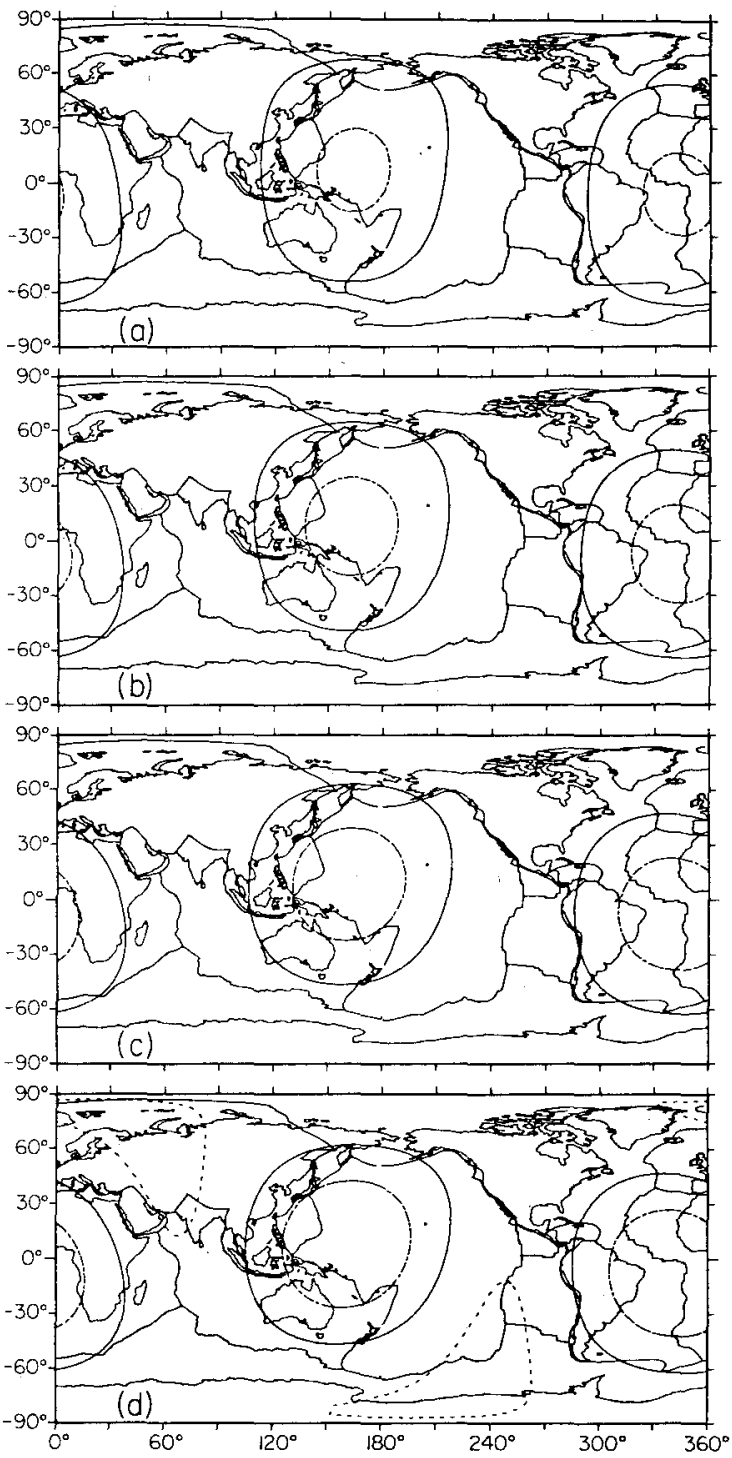

Fig. 22. Distribution of Rayleigh wave phase velocity synthesized by using the $l=2$ coefficients obtained by spherical harmonic expansion of the regionalized phase velocities. The contour interval is $0.02 \mathrm{~km} / \mathrm{s}$. Symbol conventions same as in Figure 12: (a) $148 \mathrm{~s},($ b) 200 $\mathrm{s},(c) 250 \mathrm{~s},(d) 307 \mathrm{~s}$.

contour maps synthesized by using the $l=1$ to 6 terms for the regionalized Love and Rayleigh wave phase velocities. Both even-harmonics inversions and expansion of the regionalized phase velocities suggest that the data sets of this study are sufficiently explained in terms of $l=1$ to 6 harmonics.

The even-harmonics inversions of Rayleigh waves via the use of only $l=2$ terms show high-velocity regions centered in the northwestern Pacific and the central Atlantic (Figure 14). The regionalized Rayleigh wave phase velocities (Figures 5 and 18) have high velocity in the northwestern Pacific, but not in the central Atlantic. The averaging function (23) for the $l=2$ terms tells us that we can know only an averaged property of a point and its antipode from these terms. The high velocity in the central Atlantic in Figure 14 is apparently the antipodal image of the true velocity high in the western Pacific. As Figure 22 shows, the contour maps synthesized by using only the $l=2$ terms have a pattern of velocity heterogeneity very similar to that of the $L=2$ inversions (Figure 14). This shows that the regionalized phase velocities obtained by 
TABLE 9. Coefficients of $l=2$ Spherical Harmonics of Phase Slowness, Heat Flow, and Geoid

\begin{tabular}{rrrrrrrr}
\hline & $\begin{array}{c}\text { Rayleigh*, } \\
200 \mathrm{~s}\end{array}$ & $\begin{array}{c}\text { Rayleigh*, } \\
250 \mathrm{~s}\end{array}$ & $\begin{array}{c}\text { Love*, } \\
200 \mathrm{~s}\end{array}$ & \multicolumn{1}{c}{$\begin{array}{c}\text { Love*, } \\
250 \mathrm{~s}\end{array}$} & $\begin{array}{c}\text { Heat } \\
\text { Flow 1 }\end{array}$ & $\begin{array}{c}\text { Heat } \\
\text { Flow 2 }\end{array}$ & Geoid \\
\hline$A_{20}$ & 2.2477 & 2.5378 & -1.1081 & 0.3268 & -0.472 & -2.121 & -4.4752 \\
$A_{21}$ & 2.4896 & 2.6018 & -0.3476 & -1.7482 & 0.997 & 3.832 & -0.0001 \\
$B_{21}$ & -0.1078 & 0.2924 & 5.4823 & 5.0895 & 0.788 & -0.230 & 0.0003 \\
$A_{22}$ & -5.4755 & -4.0362 & -7.7101 & -7.1691 & -3.031 & -12.398 & 2.4345 \\
$B_{22}$ & 6.4563 & 6.1464 & 4.5688 & 5.5881 & 1.396 & 5.257 & -1.3953 \\
\hline
\end{tabular}

*Unit is $10^{-4} \mathrm{~s} / \mathrm{km}$. Dynamical ellipticity [Dahlen, 1975, 1976; Dziewonski and Sailor, 1976] is corrected for by using a hydrostatic flattening $f_{h}=1 / 299.627$ [Nakiboglu, 1982].

$\dagger$ Unit is $\mathrm{mW} / \mathrm{m}^{2}$; from Chapman and Pollack [1975].

$\ddagger$ Unit is $\mathrm{mW} / \mathrm{m}^{2}$; from H. N. Pollack (private communication, 1983).

Unit is $10^{-6}$; from Nakiboglu [1982]; $f_{h}=1 / 299.627$.

using Okal's model have large-amplitude degree-two harmonics as a component of their spectrum and suggests that this is a reason for Okal's model attaining a high variance reduction of about $85 \%$ for Rayleigh waves, which is comparable to that of the $L=2$ harmonics inversion. Kawakatsu [1983] made an analysis of published regionalized phase velocities of Rayleigh waves and reached a similar conclusion.

All $L=2$ maps have one of the slow regions centered over the East Pacific Rise and one of the fast regions centered over the western Pacific. These are known from independent seismic data to be particularly slow and fast regions, respectively. The $l=2$ pattern, of course, will give symmetric antipodal anomalies of the same sign. The Red Sea-Gulf of Aden-East African Rift region is also a very low velocity region [ $\mathrm{Naka}$ nishi and Anderson, 1982], and this is nearly antipodal to the East Pacific Rise. It appears, therefore, that these regions control the $l=2$ pattern.

The preponderance of shields and the absence of rapidly spreading ridges in the high latitudes contribute a zonal term that closes off the low-velocity sectoral anomalies.

Which is the better model to represent the lateral heterogeneity of the phase velocities of long-period surface waves, $l=2$ harmonic model or Okal's regionalized model? The two models have 5 and 7 parameters, respectively, and both have almost the same variance reduction over the whole period range of this study. Thus the inversion results do not tell which model is better. The regionalization model itself is based upon knowledge of surface tectonics and the results of previous surface wave studies in oceanic regions.

\section{Comparison of the Phase Velocities With SOME Other Geophysical ObSERvations}

The lateral variation of surface wave velocity may be caused by variations in composition, mineralogy, depths of discontinuities, temperature, and so on. These lateral variations should also be observed in the variations of other geophysical observables with different kernels. The earth works as a filter, and the outputs from many inputs interfere constructively and destructively. All observations have some error. All these complicate the study of variations of the physical parameters within the earth. However, if we collect enough data, we may be able to assess the physical mechanisms that cause the lateral variations of the geophysical observables.

One of the reasons we use the spherical harmonic approach for the analysis of seismic data is to make it easy to compare them with other geophysical observations, such as heat flow and geoid, which have been expressed in terms of spherical harmonic expansions [e.g., Chapman and Pollack, 1975; Wagner et al., 1977].
Let us consider two localized heterogeneities represented by delta function

$$
\left.\begin{array}{l}
s^{0}(\Omega)=\delta\left(\Omega-\Omega_{0}\right) \\
s^{1}(\Omega)=\delta\left(\Omega+\Omega_{0}\right)
\end{array}\right\}
$$

The heterogeneity $s^{1}(\Omega)$ is located at the antipode $\left(-\Omega_{0}\right)$ of the position $\Omega_{0}$ of $s^{0}(\Omega)$. Spherical harmonic coefficients of the two heterogeneities are calculated to be

$$
\left.\begin{array}{c}
s_{l m}^{0}=Y_{l m}\left(\Omega_{0}\right) \\
s_{l m}{ }^{1}=Y_{l m}\left(-\Omega_{0}\right)
\end{array}\right\}
$$

We can obtain only the even harmonics from great circle phase velocity measurements. From the property of spherical harmonics we have

$$
s_{l m}{ }^{1}=s_{l m}{ }^{0} \quad l=\text { even }
$$

Thus the two independent localized sources of lateral variations of two different observables have the same coefficients of the $l=$ even harmonics. We have to keep in mind this result when interpreting the even harmonics.

Table 9 presents the coefficients of $l=2$ harmonics of surface wave phase slownesses, heat flow, and geoid. Heat flow coverage is sparse and Chapman and Pollack [1975] use a tectonic predictor to supplement the data. The correlation of heat flow with velocity, therefore, is another test of the tectonic-velocity correlation. The heat flow and the phase slowness data have much larger sectoral $\left(l_{m}=22\right)$ components than other components. The orientations of the nodal lines of the sectoral components are similar, especially for heat flow and Love waves. High heat flow sectors correspond to low velocity (high slowness), low heat flow sectors correspond to high velocity (low slowness). For the nonhydrostatic geoid the zonal $\left(1_{m}=20\right)$ component is the largest, the sectoral component is the next largest. The low geoid sectors coincide with high heat flow and low velocity, and vice versa. The phase velocities obtained in this study, especially Love waves, do not show large zonal harmonics. However, Masters et al. [1982] reported large-amplitude $A_{20}$ term of eigenfrequency perturbations in the period range between 200 and $400 \mathrm{sec}$ from the observations of spheroidal modes. Our Rayleigh phase velocities (Table 6) exhibit a trend that $A_{20}$ increases monotonically with period in the range from $120 \mathrm{sec}$ to $300 \mathrm{~s}$. This could be marginal because we found the increase $L=2$ to 6 in the inversions changes $A_{20}$, significantly. On the other hand, the sectoral component still predominates for the $l=2$ harmonics. A. M. Dziewonski (personal communication, 1982) made an inversion to determine $l=2$ coefficients by using the Rayleigh wave phase velocity data of Dziewonski and Steim [1982]. His 
result ( $\omega$ perturbations) shows that $-A_{20}$ increases monotonically in the period range from 180 to $350 \mathrm{~s}$. On the other hand, Masters et al.'s results show an almost constant amplitude $A_{20}$ in the same period range. Concerning their ellipticity correction they refer to Dahlen [1975], but not to the corrections noted by Dziewonski and Sailor [1976] and Dahlen [1976]. We used the results of Dziewonski and Sailor [1976] and Dahlen [1976], and Nakiboglu's [1982] corrected hydrostatic flattening $\left[f_{h}=1 / 299.627\right.$ ).

From the Love and Rayleigh wave phase velocities of our study, and the Rayleigh wave phase velocities of Dziewonski, it appears that the lateral variation of Love wave phase velocities at periods between 100 and $330 \mathrm{~s}$ and Rayleigh wave phase velocities for periods from 100 to about $250 \mathrm{~s}$ are dominated by the sectoral component. The zonal component dominates the Rayleigh wave phase velocities at periods longer than about $350 \mathrm{~s}$. The $l=2$ harmonics of the heat flow and the geoid have the largest amplitudes in the sectoral and the zonal components, respectively.

The sectoral patterns are controlled by the low phase velocities and high heat flow in the East Pacific Rise and western North America. The geoid in these regions is relatively mild, not particularly low or high. The geoid highs associated with the western Pacific subduction zones appear to control the $l=2$ geoid pattern. The center of gravity of the "subduction geoid" $\left(9^{\circ} \mathrm{N}, 135^{\circ} \mathrm{E}\right)$ is centered in the western Pacific (B. $\mathrm{H}$. Hager, unpublished manuscript, 1983), roughly $90^{\circ}$ from the East Pacific Rise. Also, on a more regional basis, geoid lows such as the Canadian Shield, western Atlantic, and Siberia are generally associated with fast upper mantle. If the $l=2$ geoid is controlled by highs in the western Pacific, and the corresponding phase velocity pattern is controlled by lows in the eastern Pacific, then one cannot use the $l=2$ information alone to determine the relationships between phase velocity and geoid. This is one of the limitations of the even-harmonic analysis. This antipodal ambiguity is reduced in the study of I. Nakanishi and D. L. Anderson (unpublished manuscript, 1983) and is not present in regionalized pure-path studies. The large-scale structure of the geoid, of course, is affected by lateral heterogeneities throughout the Earth, not just the upper mantle.

\section{Conclusions}

Our measurement and inversion of long-period Love and Rayleigh wave phase velocities lead to the following conclusions:

1. Regionalized inversion, using Okal's [1977] model (7 regions) is competitive with the $l_{\max }=2$ inversion of the great circle phase velocities of both waves. The former attains a maximum variance reduction of $65 \%$ and $85 \%$ for Love and Rayleigh waves, and the latter gives $60 \%$ and $90 \%$ maximum variance reduction, respectively.

2. Love wave regionalized phase velocities show significant variations among the seven regions. Regionalization models without lateral inhomogeneity within the ocean basins are inappropriate.

3. The Rayleigh wave results are consistent with those of previous studies that used the same regionalization.

4. Spherical harmonic expansion of regionalized phase velocities, using Okal's regionalization, show that they have $l=2$ harmonics similar to those derived directly from the great circle phase velocities by $l_{\max }=2$ harmonics inversion.

5. Both Love and Rayleigh wave phase velocities have
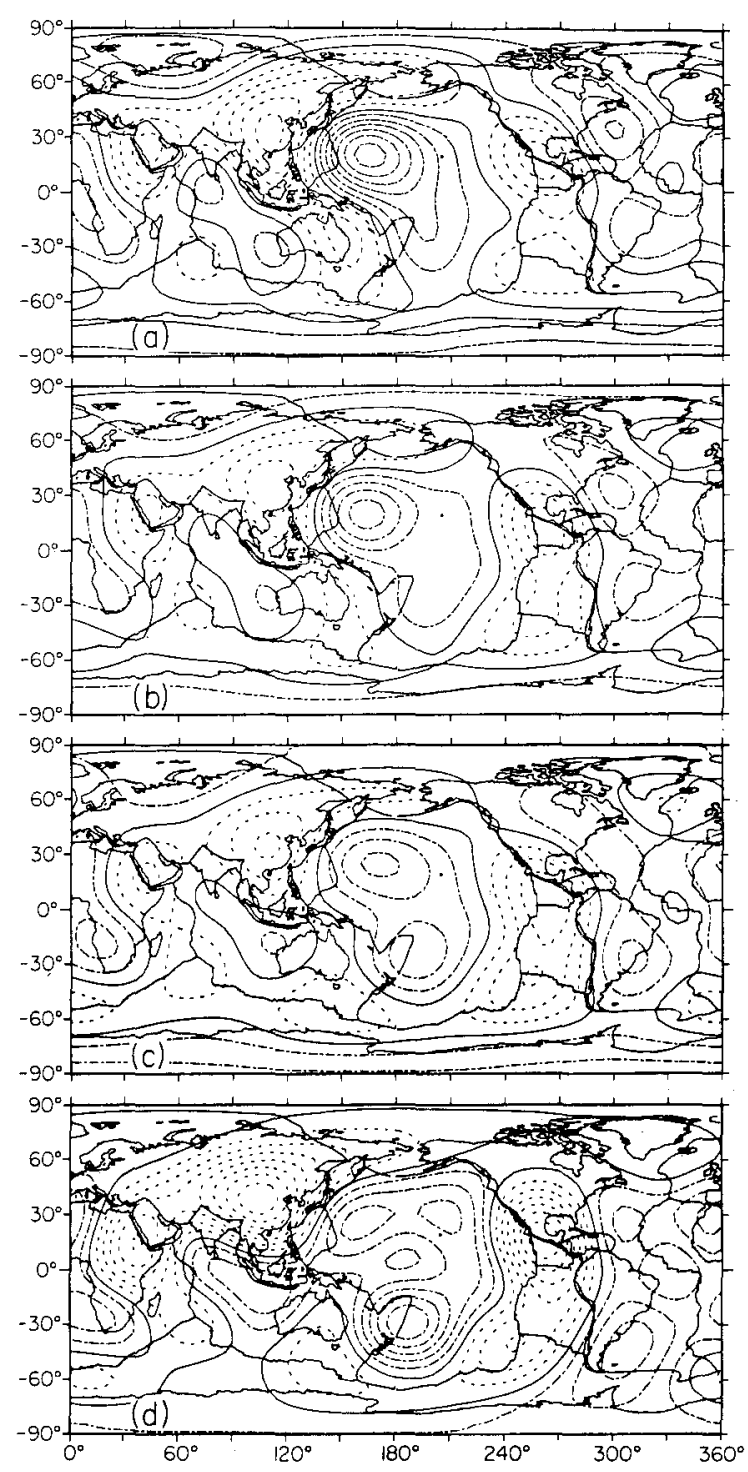

Fig. A1. Distribution of Love wave phase velocity synthesized by using the $l=1$ to 6 coefficients obtained by spherical harmonic expansion of the regionalized phase velocities. The contour interval is $0.02 \mathrm{~km} / \mathrm{s}$. Symbol conventions same as in Figure 12: (a) $148 \mathrm{~s},(b) 200$ $\mathrm{s},(c) 250 \mathrm{~s},(d) 307 \mathrm{~s}$.

$l=2$ harmonics that are dominated by the sectoral component $(l m=22)$. Of other geophysical data, the heat flow has a similar $l=2$ pattern. The nonhydrostatic geoid has a largeamplitude second-order zonal component. This feature is not seen for Love waves in the period range between 100 and 330 $\mathrm{s}$, and Rayleigh waves at periods shorter than about $250 \mathrm{~s}$, after corrections are made for dynamic ellipticity.

6. The correlation between the even harmonics of two observables does not necessarily mean that the two observables are correlated with each other, though it would be unlikely in geophysical problems that evens are correlated but odds not. To discuss the correlation between them, we need information about the odd harmonics. Great circle phase velocity or normal mode data are not sufficient for this purpose.

\section{APPENDIX}

Figures A1 and A2 present velocity contour maps synthesized by using the spherical harmonic coefficients $(l=1$ to 

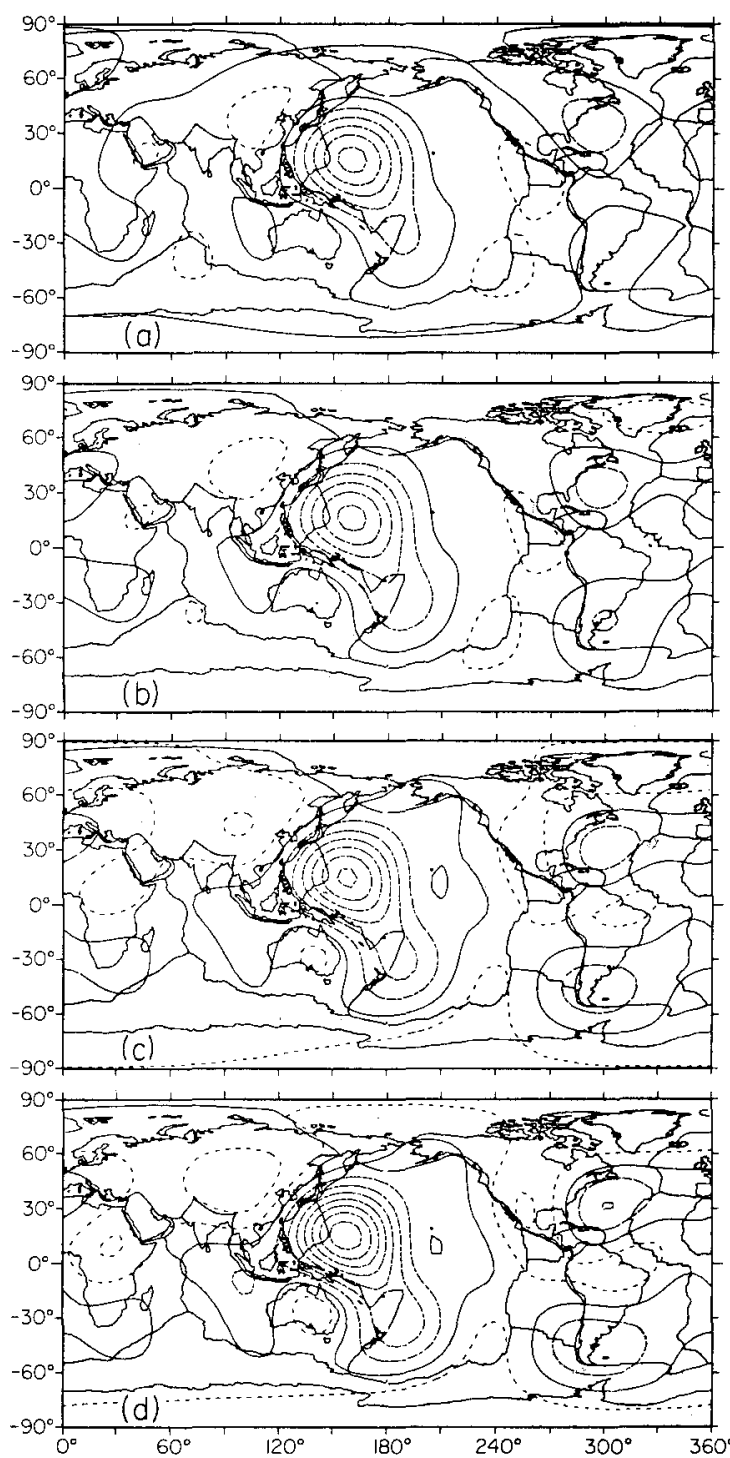

Fig. A2. Distribution of Rayleigh wave phase velocity synthesized by using the $l=1$ to 6 coefficients obtained by spherical harmonic expansion of the regionalized phase velocities. The contour interval is $0.02 \mathrm{~km} / \mathrm{s}$. Symbol conventions same as in Figure 12:(a) $148 \mathrm{~s}$, (b) 200 $\mathrm{s},(c) 250 \mathrm{~s},(d) 307 \mathrm{~s}$.

6) obtained from the expansion of the regionalized phase velocities. We made a straight truncation at $l=6$ and used the usual sum rule (7) for the synthesis.

Acknowledgments. The authors wish to thank Henri-Claude Nataf, Hiroo Kanamori, and Bradford Hager for suggestions throughout the course of this study. Jeffrey Given made important suggestions on the retrieval and the editing of GDSN data. Fumiko Tajima and Jeanne Sauber helped us retrieve the seismograms from the GDSN day tapes at an early stage of this study. Annie Souriau kindly provided a preprint of her paper on the regionalization analysis of phase velocities. Henri Pollack made a new version of heat flow spherical harmonic coefficients available to us. The IDA data used in this study were made available by courtesy of the IDA project team at the Institute of Geophysics and Planetary Physics, University of California, San Diego. We thank Bernard Minster and Adam Dziewonski for careful reviews of the manuscript. This research was supported by National Aeronautics and Space Administration grant number NSG76100 and National Science Foundation grant number EAR811-5236. Contribution number 3899, Division of Geological and Planetary Sciences, California Institute of Technology, Pasadena, California 91125.

\section{REFERENCES}

Agnew, D., J. Berger, R. Buland, W. Farrell, and F. Gilbert, International deployment of accelerometers: A network for very long period seismology, EOS Trans. AGU, 57, 180-188, 1976.

Anderson, D. L., and D. G. Harkrider, Universal dispersion tables, 2, Variational parameters for amplitudes, phase velocity, and group velocity for first four Love modes for an oceanic and a continental earth model, Bull. Seismol. Soc. Am., 58, 1407-1499, 1968.

Backus, G. E., Geographical interpretation of measurements of average phase velocities of surface waves over great circular and great semi-circular paths, Bull. Seismol. Soc. Am., 54, 571-610, 1964.

Bomford, G., Geodesy, 2nd ed., Clarendon, Oxford, 1962.

Boore, D. M., Effect of higher mode contamination on measured Love wave phase velocities, J, Geophys. Res., 74, 6612-6616, 1969.

Brune, J. N., J. E. Nafe, and L. E. Alsop, The polar phase shift of surface waves on a sphere, Bull. Seismol. Soc. Am., 51, 247-257, 1961 .

Chapman, D. S., and H. N. Pollack, Global heat flow: A new look, Earth Planet. Sci. Lett., 28, 23-32, 1975.

Dahlen, F. A., The correction of great circular surface wave phase velocity measurements for the rotation and ellipticity of the Earth J. Geophys. Res., 80, 4895-4903, 1975.

Dahlen, F. A., Reply, J. Geophys. Res., 81, 4951-4956, 1976.

Dziewonski, A. M., On regional differences in dispersion of mantle Rayleigh waves, Geophys. J. R. Astron. Soc., 22, 289-325, 1970.

Dziewonski, A. M., and D. L. Anderson, Preliminary reference Earth model, Phys. Earth Planet. Interiors, 25, 297-356, 1981.

Dziewonski, A. M., and R. V. Sailor, Comments on "The correction of great circular surface wave phase velocity measurements from the rotation and ellipticity of the earth" by F. A. Dahlen, J. Geophys. Res., 81, 4947-4950, 1976.

Dziewonski, A. M., and J. M. Steim, Dispersion and attenuation of mantle waves through waveform inversion, Geophys. J. R. Astron. Soc., 70, 503-527, 1982.

Dziewonski, A. M., J. Mills, and S. Bloch, Residual dispersion measurement-A new method of surface wave analysis, Bull. Seismol. Soc. Am., 62, 129-139, 1972.

Jordan, T. H., Global tectonic regionalization for seismological data analysis, Bull. Seismol. Soc. Am., 7I, 1131-1141, 1981.

Kanamori, H., Velocity and $Q$ of mantle waves, Phys. Earth Planet Interiors, 2, 259-275, 1970.

Kawakatsu, H., Can "pure-path" models explain free oscillation data?, Geophys. Res. Lett., 10, 186-189, 1983.

Knopoff, L., Phase and group slownesses in inhomogeneous media, $J$. Geophys. Res., 74, 1701, 1969.

Lévêque, J. J., Régionalisation du manteau supérieur à l'aide des ondes de surface de très longues périodes, Master's thesis, Univ. Paris II, France, 1978.

Lévêque, J. J., Regional upper mantle S-velocity models from phase velocities of great-circle Rayleigh waves, Geophys. J. R. Astron. Soc., $63,23-43,1980$.

Maruyama, T., On the geodesic once round the geoellipsoid (in Japanese), Zisin, 20, 50-53, 1967.

Masters, G., T. H. Jordan, P. G. Silver, and F. Gilbert, Aspherical earth structure from fundamental spheroidal-mode data, Nature, 298, 609-613, 1982.

Mills, J. M., Great-circle Rayleigh wave attenuation and group velocity, Part 4, Regionalization and pure-path models for shear velocity and attenuation, Phys. Earth Planet. Interiors, 17, 323-352, 1978.

Nakanishi, I., Phase velocity and $Q$ of mantle Rayleigh waves, Geophys. J. R. Astron. Soc., 58, 35-59, 1979.

Nakanishi, I., and D. L. Anderson, World-wide distribution of group velocity of mantle Rayleigh waves as determined by spherical harmonic inversion, Bull. Seismol. Soc. Amer., 72, 1185-1194, 1982.

Nakanishi, I., and H. Kanamori, Effects of lateral heterogeneity and source process time on the linear moment tensor inversion of longperiod Rayleigh waves, Bull. Seismol. Soc. Amer., 72, 2063-2080, 1982.

Nakiboglu, S. M., Hydrostatic theory of the earth and its mechanical implications, Phys. Earth Planet. Interiors, 28, 302-311, 1982.

Okal, E. A., The effect of intrinsic oceanic upper-mantle heterogeneity on regionalization of long-period Rayleigh-wave phase velocities, Geophys. J. R. Astron. Soc., 49, 357-370, 1977.

Satô, Y., Attenuation, dispersion, and the wave guide of the $G$ wave, Bull. Seismol. Soc. Am., 48, 231-251, 1958.

Schlue, J. W., Anisotropy of the upper mantle of the Pacific Basin, Ph.D. thesis, Univ. Calif., Los Angeles, 1975. 
Silver, P. G., and T. H. Jordan, Fundamental spheroidal mode observations of aspherical heterogeneity, Geophys. J. R. Astron. Soc., 64, 605-634, 1981.

Souriau, A., and M. Souriau, Test of tectonic models by great circle Rayleigh waves, Geophys J. R. Astron. Soc., 73, 533-551, 1983.

Thatcher, W., and $\mathbf{J}$. N. Brune, Higher mode interference and observed anomalous apparent Love wave phase velocities, J. Geophys. Res., 74, 6603-6611, 1969.

Toksöz, M. N., and D. L. Anderson, Phase velocities of long-period surface waves and structure of the upper mantle, 1. Great-circle Love and Rayleigh wave data, J. Geophys. Res., 71, 1649-1658, 1966.

Umbgrove, J. H. F., The Pulse of the Earth, 2nd ed., Nijhoff, The Hague, 1947.

Wagner, C. A., F. J. Lerch, J. E. Brownd, and J. A. Richardson, Improvement in the geopotential derived from satellite and surface data (GEM 7 and 8), J. Geophys. Res., 82, 901-914, 1977.
Whaler, K. A., and D. Gubbins, Spherical harmonic analysis of the geomagnetic field: An example of a linear inverse problem, Geophys. J. R. Astron. Soc., 65, 645-693, 1981.

$\mathrm{Wu}, \mathrm{F}$. T., Mantle Rayleigh wave dispersion and tectonic provinces, J. Geophys. Res., 77, 6445-6453, 1972.

Zharkov, B. N., and V. M. Lyubimov, The theory of spheroidal vibrations for a spherically asymmetric model of the earth, Izvestiya, Phys. Solid Earth, 10, 613-618, 1970.

D. L. Anderson, Seismological Laboratory, California Institute of Technology, Pasadena, CA 91125.

I. Nakanishi, Research Center for Earthquake Prediction, Faculty of Science, Hokkaido University, Sapporo, 060, Japan.

(Received June 1, 1983;

revised August 25, 1983;

accepted September 1, 1983.) 